\title{
A four-dimensional analysis of the thermal structure in the Gulf of Lion
}

\author{
Fabienne Gaillard and Yves Desaubies \\ Laboratoire de Physique des Océans, IFREMER, Plouzané, France \\ Uwe Send and Fritz Schott \\ Institut für Meereskunde, Kiel, Germany
}

\begin{abstract}
The Theoretical and Experimental Tomography in the Sea Experiment (THETIS 1) took place in the Gulf of Lion to observe the evolution of the temperature field and the process of deep convection during the 1991-1992 winter. The temperature measurements consist of moored sensors, conductivity-temperature-depth and expendable bathythermograph surveys, and acoustic tomography. Because of this diverse data set and since the field evolves rather fast, the analysis uses a unified framework, based on estimation theory and implementing a Kalman filter. The resolution and the errors associated with the model are systematically estimated. Temperature is a good tracer of water masses. The time-evolving three-dimensional view of the field resulting from the analysis shows the details of the three classical convection phases: preconditioning, vigourous convection, and relaxation. In all phases, there is strong spatial nonuniformity, with mesoscale activity, short timescales, and sporadic evidence of advective events (surface capping, intrusions of Levantine Intermediate Water (LIW)). Deep convection, reaching $1500 \mathrm{~m}$, was observed in late February; by late April the field had not yet returned to its initial conditions (strong deficit of LIW). Comparison with available atmospheric flux data shows that advection acts to delay the occurence of convection and confirms the essential role of buoyancy fluxes. For this winter, the deep mixing results in an injection of anomalously warm water $\left(\Delta T \simeq 0.03{ }^{\circ}\right)$ to a depth of $1500 \mathrm{~m}$, compatible with the deep warming previously reported.
\end{abstract}

\section{Introduction}

Deep convection is one of the key processes in ocean thermohaline circulation. Typically, it occurs during winter, at high latitudes, where it is difficult to observe in detail, although there have been some notable exceptions: in the Labrador Sea [Clark and Gascard, 1983] and in the Greenland Sea [Greenland Sea Project (GSP) Group, 1990; Schott et al., 1994]. A more accessible site is the Gulf of Lion, in the northwestern Mediterranean, where convection is known to occur regularly, under the cooling action of strong winds (the Mistral and the Tramontane).

The Mediterranean Sea circulation is to a large extent controlled by thermohaline effects. It is an evaporation basin where the excess of evaporation over precipitation (plus river runoff) is of order $1 \mathrm{~mm} \mathrm{yr}^{-1}$. The water deficit is made up by an inflow of Atlantic surface water, and the overall heat and salt balance is achieved by a corresponding outflow of Mediterranean water through the Straits of Gibraltar. Although the exact nature

Copyright 1997 by the American Geophysical Union.

Paper number 96JC03821.

0148-0227/97/96JC-03821\$09.00 of the water masses flowing out at Gibraltar is not clearly identified (a mixture of Levantine Intermediate Water (LIW) and of Western Mediterranean Deep Water (WMDW) [Gascard and Richez, 1985]), they are the product of the transformations and conversions undergone by the surface waters of Atlantic origin during their circulation in the western and eastern basins. One element is the formation of LIW in the eastern basin [Ozturgut, 1976], the other, the formation of WMDW, is thought to occur mostly in the Gulf of Lion (although some occurs probably also in the Ligurian Sea [Sankey, 1973]).

Because of this relatively simple dynamics and the possibility to monitor the budgets of mass, heat, and salt at the Straits of Gibraltar, one would hope to be able to use the Mediterranean as a testbed of models of large-scale air-sea interaction. In fact, there have been attempts to calibrate atmospheric fluxes and radiative balance models on the Mediterranean Sea budgets [Garrett, 1994]; the uncertainties in the surface fluxes are such that the models can be tuned to obtain a balanced budget. Thus there is great interest and motivation to observe the interaction processes in some detail.

Winter convection in the Gulf of Lion has been extensively studied in the 1970 s, during the Mediterran'ee oc- 
cidentale (MEDOC) cruises (1969-1975). The analysis which followed [MEDOC Group, 1970; Stommel, 1972; Sankey, 1973; Gascard, 1973] lead to the schematic scenario in three phases.

(1) - The preconditioning produces a decrease of buoyancy in the center of the gulf. It was attributed to topographic effects by Hogg [1973] but is more likely due to the cyclonic mean geostrophic circulation which confines a large body of water, exposing it to the local cooling by Mistral and Tramontane. The associated shoaling of the isopycnals at the center of the area also increases the penetration of the cooling.

(2) - Toward midwinter (January), the stability ot the water column is greatly reduced, so that additional surface cooling precipitates deep convection, which rapidly spreads to an area of about $50 \mathrm{~km}$ in diameter. This is the violent mixing phase. This mixing appears to be primarily vertical and is characterized as "nonpenetrative" convection by Stommel [1972].

(3) - The columnar structure of the homogeneous patch will then spread and sink, providing newly formed waters to the deep layers.

Killworth [1976] modeled the mixing and spreading phases. With a two-dimensional model he demonstrated that during the violent mixing phase, ageostrophic movements perpendicular to the column frontier advect light water toward the center and reduce the cooling by $15 \%$. Following this phase, after 10 days of cooling, three-dimensional perturbations of the preceeding solution develop instabilities with 3.5 days $e$ folding times. This idea of competition between vertical and horizontal effects was further developed by Gascard [1978]. On the basis of the MEDOC 75 data, Gascard built a two-layer model. He noticed that, as soon as the central doming is sufficiently developed, meanders start to grow through baroclinic instability, leading to horizontal exchange of water masses between the cyclonic vortex and the surrounding waters.

The technological improvements performed since the MEDOC cruises have motivated a new interest for observations in the convection areas. Leaman and Schot [1991] and Schott and Leaman [1991] report a strong convective event during the winter of 1987 , where vertical velocities of $5-10 \mathrm{~cm} \mathrm{~s}^{-1}$ were measured with acoustic Doppler current profilers (ADCPs). In the winter of 1991-1992, an international experiment, codenamed Theoretical and Experimental Tomography in the Sea Experiment (THETIS 1), took place in that same area, where a diversity of observational techniques were implemented: conductivity-temperaturedepth (CTD) and expendable bathythermograph (XBT) surveys, moored temperature, salinity and current records (ADCPs and Aandera) and acoustic tomography, [THETIS Group, 1994]. Surface forcing for this period was available through the outputs of the Méteo France Péridot model. One of the goals of THETIS 1 was to resolve the wide range of spacescales and timescales of the processes taking place through the winter and to relate the evolution of the field to the surface forcing. Schott et al. [1994] describe the classical sequence of events leading to convection. The return to the initial stratified conditions had not occurred at the end of the experiment in late April.

The analysis of the acoustic and temperature data set by Send et al. [1995], hereafter SSGD, showed clearly the evolution of the mean heat content in the upper layers, the occurrence of convection in mid February (to a depth of $1500 \mathrm{~m}$ ), and the rapid changes in the thermal structure. One unexpected aspect was the occasional spreading over part of the area of a warm surface layer (capping), which could temporarily delay convection or, after its occurence, move over the deeply mixed patch. Comparison of the ocean heat content with a simple one-dimensional mixed layer model [Mertens, 1994] driven by the Péridot fluxes gave good overall agreement at some locations, although the presence of warm surface layers indicated the occurence of advection into the area.

A more detailed description by Schott et al. [1995] related specific events, as seen in the various CTD stations or in the time series at the mooring locations, to the chain of events leading to the onset of deep convection and shortly thereafter. They documented in particular the action of the small-scale $(\simeq O(500 \mathrm{~m}))$ convective plumes as mixing agents, with vertical velocity reaching $5 \mathrm{~cm} \mathrm{~s}^{-1}$, but without evidence of a net downdraft vertical motion over the area. Mixing, to depths of $1500 \mathrm{~m}$, was described as nonpenetrative (no density jump at the base of the mixed layer) and highly heterogeneous over the area, which was 50 to $100 \mathrm{~km}$ in extent. The presence of lateral variability and horizontal advection associated with mesoscale activity was pointed out.

In this paper, the THETIS 1 data are again considered, with a focus on the time evolution of the threedimensional temperature field. Temperature measurements are selected because they constitute the largest data set, and temperature turns out to be an excellent marker of water masses. It is necessary to adopt a unified method of analysis for the different data types because of the rapid changes in the field, of the range of scales involved, and of the diversity of measurements available. CTD surveys, for instance, cannot be considered to be synoptic. A standard inverse procedure is applied, in conjunction with a Kalman filter which accounts for time evolution in the form of persistence. Thus all the data are incorporated under the same assumptions on their scales of variability. Inevitably, some filtering of the field results from this approach, but one can always return to the original measurement to observe a given local process [Schott et al., 1995]).

The method developed for our analysis is presented in section 2. Then we describe the time evolution of the analyzed temperature field over the observed domain (section 3), showing the classical phases of convection in a three-dimensional approach. Finally, in section 4, we quantify the relation to the atmospheric forcing with the help of a simple mixed layer model. The heat and buoyancy budgets are calculated with the parameters provided by the Péridot model. 


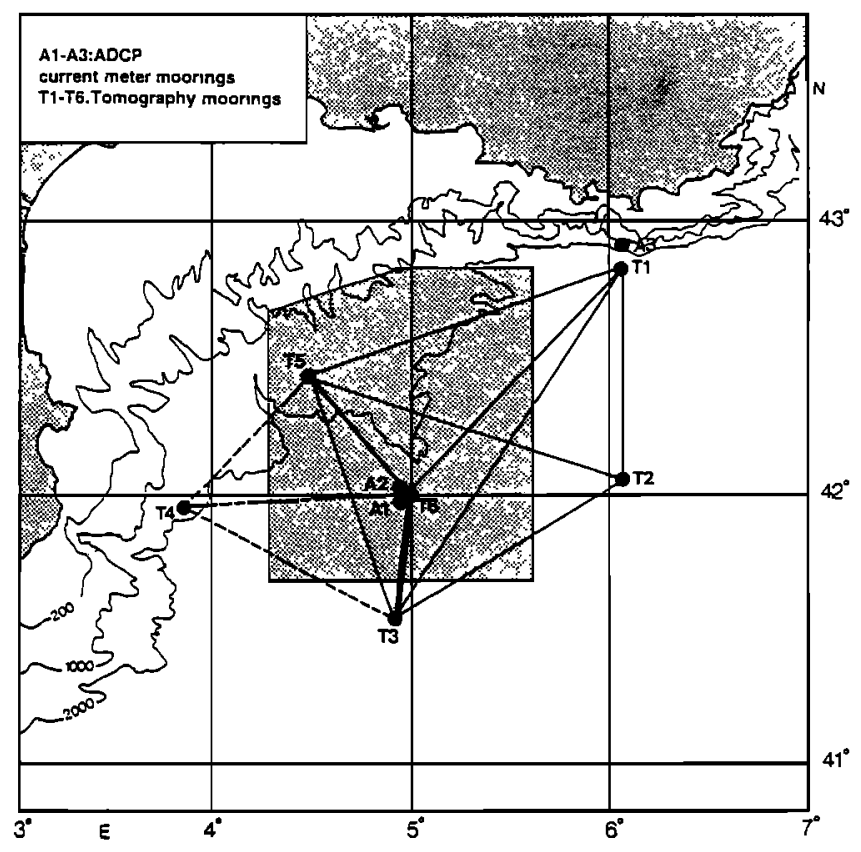

Figure 1. Moorings position during THETIS 1. A1 to $\mathrm{A} 3$, current meter moorings; $\mathrm{T} 1$ to $\mathrm{T} 6$, tomography moorings. The shaded area defines the "central area" over which averages are performed.

\section{The Analysis}

\subsection{The Temperature Data Set}

During the THETIS 1 experiment (Figure 1) a large volume of data has been collected in the Gulf of Lion with various measuring devices: CTD with tracers casts, moored current meters and temperature sensors and tomographic transceivers. These data sets differ in their way of sampling the ocean, but many of them have in common a measure of temperature: either direct or through a state equation (the speed of sound). The lack of similarities in the space and time spectral windows attached to each data set makes any analysis based on comparisons difficult. The problem of inadequate sampling is illustrated by the classical way of using CTD data: in order to access the horizontal structure of the field, the data collected during a cruise are assumed synoptic, and it is hard to distinguish, in the reconstructed maps, the relative contribution of time and space variability. The present approach takes explicitly into account the nature of the sampling and exploits the complementarity of the data sets. We choose to recon- struct a temperature field defined by a finite number of parameters characterizing its horizontal resolution, vertical representation, and timescale. Each data set is used to constrain the field through a relation defining its influence on the parameters of the field. This relation contains implicitly the date and position of the measurement. With such a process, all the information about the temperature field which projects on the space described by the parameters is extracted from the data.

Four data sets have been selected as providing temperature information. The CTD and XBT data are vertical profiles at single points in the horizontal and at single times. The fixed point temperature sensors give good temporal coverage but at single points in the three space dimensions. These first three data types are usually refered to as "direct measurements", but the terminology: "point measurements" would be more accurate. The last data set is provided by the tomographic measurements. They are "integral data" available with good time resolution. The measured travel times are inversely related to the sound speed encountered along the path of the acoustic rays. The validation and evaluation of this data set are exposed by SSGD. The mooring positions are plotted on Figure 1; they were set up in three arrays, each with a specific goal: (1) The tomography array (moorings T1 through T6) covered the area where convection was expected. (2) The small-scale array was set at the expected center of the convection patch (A1, A2, T6). (3) The boundary array was meant to measure inflow conditions $(A 3, T 1)$.

The THETIS 1 hydrographic measurements were performed during five cruises, sampling the different stages of winter convection from late November to April. A total of 216 deep CTD stations, 43 XBTs and 30 expendable CTDs (XCTDs) were collected. The dates and number of data per cruise are summarized in Table 1 , the corresponding station positions are shown in Figure 2. At each cruise, it was attempted to repeat the sections $5^{\circ} \mathrm{E}, 6^{\circ} \mathrm{E}$, and $42^{\circ} \mathrm{N}$. Table 2 gives an overview of the vertical and temporal coverage provided by the temperature recording, while Table 3 summarizes the spatial extension of the tomographic array by listing the periods covered by each tomographic pair.

\subsection{Implementation of the Method}

Our goal is to reconstruct the evolution of the temperature field over the duration of the experiment from data sets characterized by spectral contents which differ both in time and space. The "state vector" is defined

Table 1. Hydrographical Profiles Collected During THETIS 1.

\begin{tabular}{crrrrr}
\hline Cruise & \multicolumn{1}{c}{ Beginning } & \multicolumn{1}{c}{ End } & CTDs & XBTs & XCTDs \\
\hline & & & & & \\
Suroît 1 & Nov. 27, 1991 & Dec. 1, 1991 & 28 & & \\
Valdivia & Dec. 8, 1991 & Dec. 19, 1991 & 24 & 13 & \\
Suroît 2 & Jan, 8, 1992 & Jan. 16, 1992 & 38 & & \\
Poseidon & Feb. 18, 1992 & March 3, 1992 & 99 & 20 & 30 \\
Suroît 3 & April 13, 1992 & April 26, 1992 & 27 & & \\
\hline
\end{tabular}


Suroit 1

27/11-01/12/91
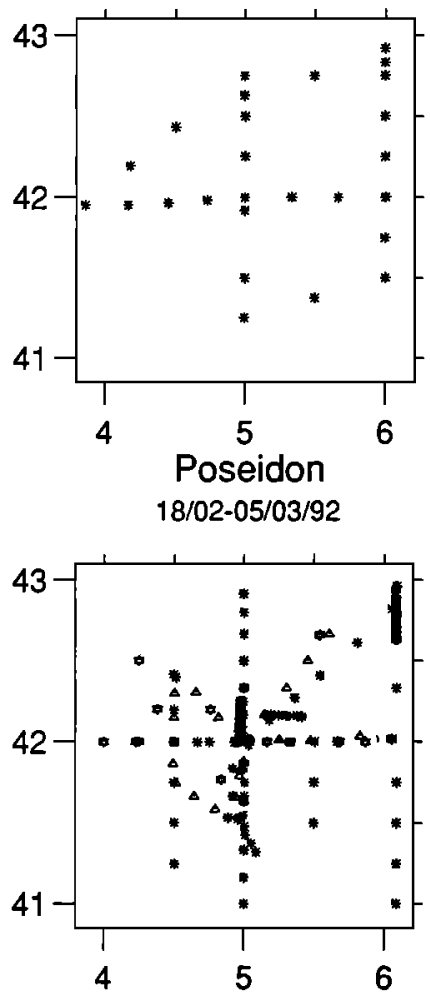

Valdivia

$08 / 12-19 / 12 / 91$

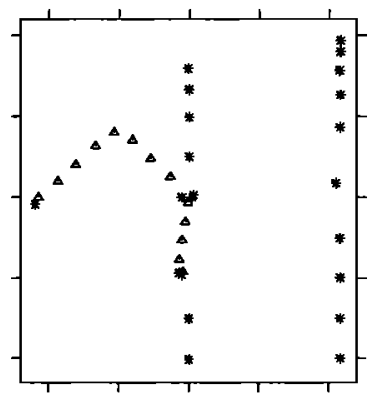

Suroit 3

$13 / 04-26 / 04 / 92$

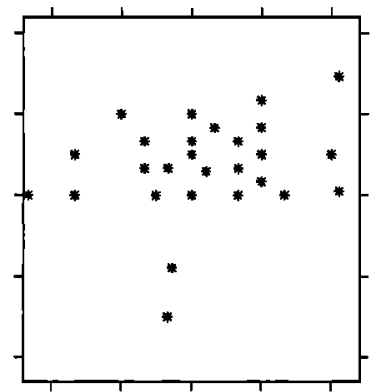

Suroit 2

08/01-16/01/92

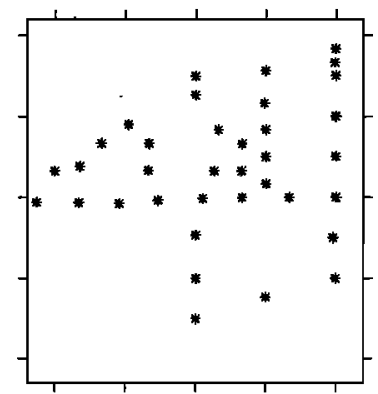

Thetis 1 cruises

* CTD

$\triangle \quad \mathrm{XBT}$

- XCTD

Figure 2. Position of hydrographical measurements during the five THETIS 1 cruises of the 1991-1992 winter.

Table 2. Summary of Fixed Point Temperature Series

\begin{tabular}{|c|c|c|}
\hline Mooring & Depth, $n$ & Period \\
\hline \multirow[t]{5}{*}{$\mathrm{T} 1$} & 80 & Dec. 11 to April 20 \\
\hline & 200 & Dec. 11 to April 20 \\
\hline & 500 & Dec. 11 to April 20 \\
\hline & 1000 & Dec. 11 to April 20 \\
\hline & 1500 & Dec. 11 to April 20 \\
\hline \multirow[t]{4}{*}{$\mathrm{T} 2$} & 100 & Dec. 8 to Feb. 8, Feb. 29 to April 25 \\
\hline & 250 & March 1 to April 25 \\
\hline & $250-650$ & Dec. 11 to April 20 \\
\hline & 1000 & Dec. 8 to Feb. 8, Feb. 29 to April 25 \\
\hline \multirow[t]{3}{*}{ T3 } & 100 & Dec. 6 to April 15 \\
\hline & $250-650$ & Dec. 6 to Feb. 01 , March 3 to April 15 \\
\hline & 1000 & Dec. 6 to April 15 \\
\hline $\mathrm{T} 4$ & 360 & Dec. 6 to April 26 \\
\hline \multirow[t]{4}{*}{ T5 } & 85 & Feb. 23 to April 22 \\
\hline & 160 & $\begin{array}{l}\text { Dec. } 15 \text { to Jan. } 26 \text {, Feb. } 26 \text { to March } 13 \\
\text { March } 31 \text { to April } 11\end{array}$ \\
\hline & 370 & Dec. 5 to Feb. 11 \\
\hline & $250-650$ & Feb. 26 to April 22 \\
\hline $\mathrm{T} 6$ & 1020 & Dec. 12 to April 24 \\
\hline \multirow[t]{7}{*}{ A1 } & $50-250$ & Dec. 13 to Feb. 9 \\
\hline & 318 & Dec. 13 to April 24 \\
\hline & 322 & Dec. 13 to Feb. 9 \\
\hline & 720 & Dec. 13 to Feb. 9 \\
\hline & 1000 & Dec. 13 to April 24 \\
\hline & 1005 & Dec. 13 to April 24 \\
\hline & 1400 & Dec. 13 to April 24 \\
\hline A2 & 1000 & Dec. 13 to April 24 \\
\hline $\mathrm{A} 3$ & 500 & Dec. 10 to April 20 \\
\hline
\end{tabular}

as a finite set of parameters, efficiently representing the features of the field under study. The value of these parameters will then be estimated from the available data set at a discrete number of instants. The choice of a state vector is obviously conditioned by the field we wish to estimate, but it also depends strongly on the data type and sampling available. Conversely, the esti-

Table 3. Summary of the tomographic pair series

\begin{tabular}{|c|c|c|}
\hline Pair & Name & Period \\
\hline 1 & $\mathrm{~T} 1-\mathrm{T} 2$ & Dec. 15-19, March 4 to April 10 \\
\hline 2 & T1-T3 & Dec. 15 to Jan. 1, March 4 to April 10 \\
\hline 3 & T1-T4 & Dec. 15-18, March 4 to April 10 \\
\hline 4 & T1-T5 & $\begin{array}{l}\text { Dec. } 15 \text { to Jan. 1, March 4-12, } \\
\text { March 31-April } 10\end{array}$ \\
\hline 5 & T1-T6 & Dec. 15 to Jan. 1, March 4 to April 10 \\
\hline 6 & T2-T3 & Dec. $15-19$, March 2 to April 10 \\
\hline 7 & $\mathrm{~T} 2-\mathrm{T} 4$ & Dec. $15-18$ \\
\hline 8 & T2-T5 & Dec. $15-19$, March 2 to April 10 \\
\hline 9 & $\mathrm{~T} 2-\mathrm{T} 6$ & Dec. $15-19$, March 2 to April 10 \\
\hline 10 & T3-T4 & Dec. $15-18$ \\
\hline 11 & T3-T5 & Dec. 15 to Jan. 26 , Feb. 27 to April 10 \\
\hline 12 & T3-T6 & Dec. 15 to Feb. 11 , Feb. 29 to April 10 \\
\hline 13 & T4-T5 & Dec. $15-18$ \\
\hline 14 & T4-T6 & Dec. $15-18$ \\
\hline 15 & T5-T6 & $\begin{array}{l}\text { Dec. } 15 \text { to Jan. } 26, \text { Feb. } 29 \text { to March } 12 \text {, } \\
\text { March } 31 \text { to April } 10\end{array}$ \\
\hline
\end{tabular}


mation procedure relies on a model defining the relation between the data vector and the state vector.

2.2.1. Definition of the state vector. Despite intermittent failures, the tomographic data set ensures the most global coverage of the area of interest both in time and space. The tomographic measurements are integral functions of sound speed, closely related to temperature. We have deduced from the THETIS 1 CTD database a linear relationship between a sound speed perturbation and the corresponding temperature perturbation in the form

$$
\delta C(x, y, z, t)=\alpha(z) \delta T(x, y, z, t)
$$

The vertical profile $\alpha(z)$ deduced from a fit to the CTD data set is shown in Figure 3. The RMS relative error made in representing $\delta T$ from (1) is $10 \%$ from 0 to $100 \mathrm{~m}, 6 \%$ from 100 to $500 \mathrm{~m}, 2 \%$ from 500 to 1000 $\mathrm{m}, 4 \%$ from 1000 to $1500 \mathrm{~m}$, and $20 \%$ below $1500 \mathrm{~m}$. The slightly higher surface error is due to mixing which modifies the T-S relationship. The large deep value for the relative error corresponds to a decrease of the $\delta T$ variance, not to an increase of the error. In the following the sound speed and temperature variable will be considered as perfectly equivalent. The tomographic data set being the core of our observing system, the state vector $x$ is defined in terms of sound speed, the results being later converted to temperature by (1). This choice, based on computational convenience criteria, has little influence on the results.

In order to deal with a reduced number of parameters, the sound speed anomaly $\delta C$ is projected on a limited number of vertical modes. The most efficient representation is ensured by taking the first empirical orthogonal functions (EOFs). The principal components analysis is performed on the sound speed profiles deduced from the CTD data set. The modes' efficiency for representing the sound speed perturbation can be measured through the percentage of total variance represented. In THETIS 1, the first five modes, shown in Figure 3, rep- resent $96.6 \%$ of the total variance. The main features of the vertical structure variability are clearly seen; they are linked to the surface layers, Levantine Intermediate Water, and deep convection variability which, during this 1991-1992 winter, only reached $1700 \mathrm{~m}$. CTD data were used to test the vertical basis and typical profiles of sound speed anomaly were reconstructed with five modes: as expected, the sharp gradients are smoothed off, but the main features are represented.

The vertical mode coefficients, representing the horizontal variations of the field, are decomposed in a truncated Fourier series. This type of representation has been implemented and evaluated in a previous simulation [Gaillard, 1992]. The horizontal fields for each mode are computed in a square box $256 \mathrm{X} 256 \mathrm{~km}$, centered at $42.25^{\circ} \mathrm{N}-5.00^{\circ} \mathrm{E}$. This box is wider than the "observation area" to avoid periodicity effects, and only the central area constrained by observations will be analyzed. A circular truncation is performed at wavenumber $|k|<8$. The cutoff wavelength is $\lambda_{c}=32 \mathrm{~km}$ equivalent to a cutoff length scale $L_{c}=\lambda_{c} /(2 \pi)=5 \mathrm{~km}$. The mean vertical density profile, computed from the November and December CTDs, gives a first Rossby radius $R_{1}=5.7 \mathrm{~km}$. The $|k|<8$ truncation resolves this scale. Accessing the second Rossby radius $(2.8 \mathrm{~km})$ would require setting the truncation at $k=15$, which considerably increases the number of parameters to be estimated and is beyond the resolution provided by the data set.

2.2.2. Data vector and inverse model. Estimating a set of parameters from data constraints under least squares criterion is a classical inverse problem. In our case, a full set of parameters describing the state of the temperature field (the state vector) is estimated at each time step. Rather than performing independent inversions, each starting with climatology as first guess, a simplified version of a Kalman filter procedure is applied. With such a method the time evolution is taken into account through a linear prediction of the first guess and initial covariances. The simplifications
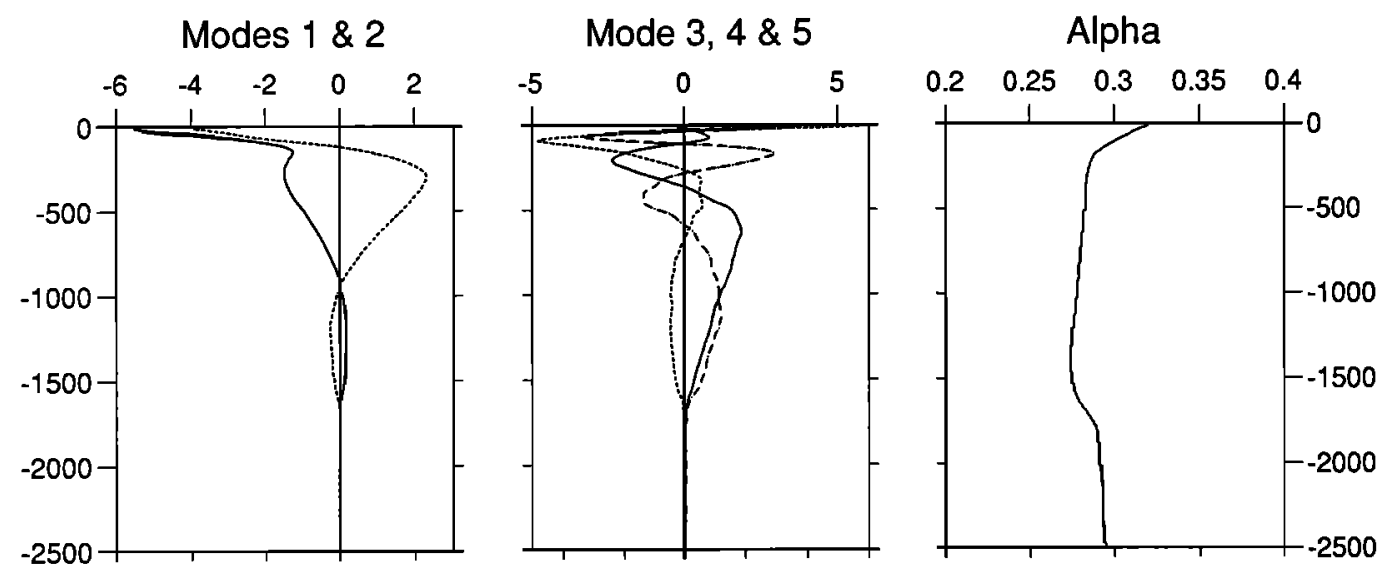

Figure 3. Vertical modes (EOF) for sound speed anomalies (left and middle panels). Vertical profile of $\alpha(\mathrm{z})$, used to convert temperature perturbation in sound speed perturbation (right panel). 
taken here are (1) to assume persistence of the field with relaxation toward climatology as a prediction equation and (2) to use a constant form for the prediction error. Details about the method are given in Appendix A. One step in the estimation combines a forecast step and an updating step. As a 12-hour time step is chosen, each data series is sampled accordingly. The temperature time series collected are converted into series of sound speed anomaly $\delta C$ using equation (1). The corresponding constraint writes:

$$
\delta \hat{C}\left(x_{i}, y_{i}, z_{i}, t\right)=\delta C\left(x_{i}, y_{i}, z_{i}, t\right)+\epsilon_{i}
$$

The vertical profiles from CTDs and XBTs are converted to sound speed with the Chen-Millero formula. The salinity variable, which is missing from the XBT data, is deduced from a T-S relationship of the form $S=f(T, z)$ established from the CTDs. For these vertical profiles, two strategies are applied: (1) The $\delta C$ profiles deduced from the CTDs deeper than $1500 \mathrm{~m}$ are projected on the five vertical modes. The five coefficients obtained are introduced as five constraints. They are called the mode data. (2) All the CTD+XBT profiles are also used as layer constraints. The mean sound speed perturbation is computed for six layers, limited by the levels: $0,100,300,500,700,1000$, and $1500 \mathrm{~m}$. The deep CTD profiles appear twice in the data vector, once in the form of five mode coefficients and once in the form of six layer averages. Although the model is only capable of reconstructing the field over five modes, we consider that this ensures a better use of the CTD information.

For the tomography data, a simple linear relationship is assumed. The mean travel time perturbation of a particular arrival $i$, measured relative to a predicted travel time $t t_{i}^{0}$, is related to the sound speed perturbation field $\delta C(x, y, z)$, relative to a mean sound speed $\bar{C}(z)$ :

$$
\delta t t_{i}=\frac{t t_{i}^{+}+t t_{i}^{-}}{2}-t t_{i}^{0}=-\int_{\Gamma,} \frac{\delta C(x, y, z)}{\bar{C}^{2}(z)} d s
$$

This relation results from a linearization which holds in our case where the distances are short and the ray paths stable for the sound speed perturbations encountered.

The strength of each data constraint is controlled by the data covariance matrix (see Appendix A for details). For layer constraints and time series the a priori variance of the data is deduced from the measurement error; Table 4 summarizes the characteristics of the errors

Table 4. A priori Errors on the Data (Instrumental and From Processing)

\begin{tabular}{lcrr}
\hline \multicolumn{1}{c}{ Data Type } & Unit & $\epsilon \min$ & $\epsilon \max$ \\
\hline Tomography & $10^{-3} \mathrm{~S}$ & 1.2 & 14.0 \\
Temperature series & ${ }^{\circ} \mathrm{C}$ & 0.01 & 0.03 \\
Mode coefficients (deep CTDs) & & 0.02 & 0.02 \\
Layer averages (CTDs, XBTs) & $\mathrm{m} \mathrm{S}^{-1}$ & 0.02 & 0.2 \\
& & & \\
\hline
\end{tabular}

Available data

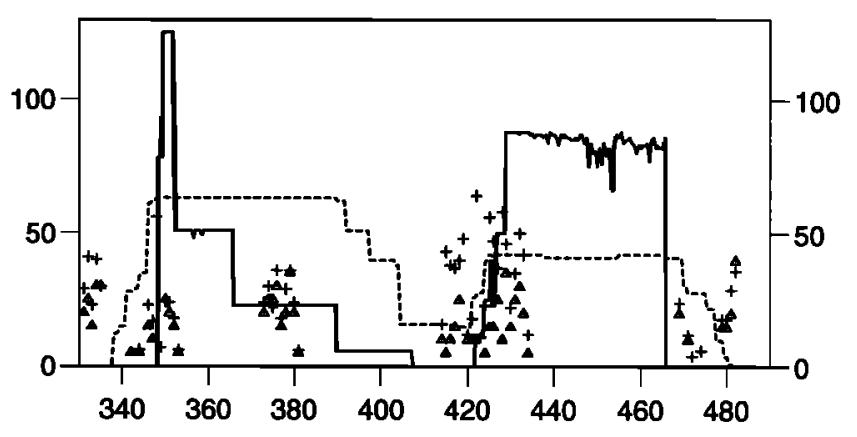

RMS residuals

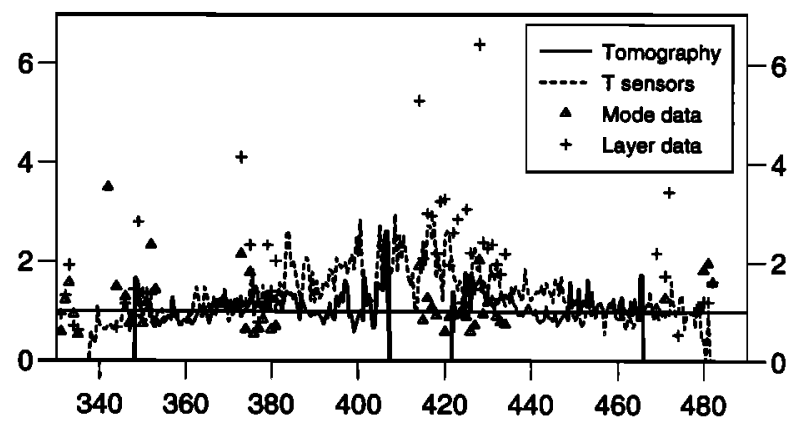

Figure 4. Contribution of each data type along the duration of the experiment (in year days since January 1 1991). (top) Number of available data at each time step. (bottom) RMS value of the signal to noise residuals.

for each of these data type. The "mode" constraints a priori variance is more difficult to estimate. The RMS value of the coefficients varies from 0.77 for mode 1 to 0.17 for mode 5 ; an error of 0.02 is assumed on each mode coefficient.

\subsection{First Diagnostics}

The model is run from November 28 (day 331) to April 15 (day 480) with a half day time step. An overview of the data available at each time step is given in Figure 4, which shows the number of data elements, for each data type, as a function of time. In this representation, there is no information about the weight of this data. One acoustic ray path is considered as one piece of data, one temperature sensor is considered as one piece of data regardless of vertical coherence between all sensors of a thermistor chain, one XBT or shallow CTD provides four to six layer data depending on depth, and one CTD deeper than $1500 \mathrm{~m}$ gives five mode plus six layer data. Despite the various failures in the time series recording, only days from February 13 to 18 are poorly sampled with only 16 temperature sensors operating.

A global evaluation of the compatibility of our data set and model is obtained through the linear residuals $\left(y_{n}-G_{n} \hat{x}_{n}\right)$. This quantity measures how well each data constraint is satisfied by the estimated field $\hat{x}$ for the defined model $G$. The RMS values of the residuals are computed at each time step separately for each 
data type, and they are presented in Figure 4, normalized by the a priori error. Assuming that the noise has been correctly estimated from the various calibrations, a residual to noise ratio close to 1 indicates good agreement between the data, model, and a priori hypothesis. The tomography data meet this compatibility requirement except for a few events. Those events correspond to periods of poor signal to noise ratio in the acoustic recordings during which the tracking algorithm may have failed. The temperature data residuals show highfrequency peaks during the period of strongest penetration of the vertical mixing (January 21 to March 6 or days $385-430$ ). They reflect the inability of the model to represent the small horizontal and vertical scales captured by the point measurements. The data issued from the vertical profiles behave differently depending on the way they are entered into the model. When entered as mode coefficients, these data are perfectly satisfied with a residual to noise ratio lower than 1 . When the information is provided as a mean layer perturbation, part of this information cannot be projected on the truncated vertical basis and remains in the residuals. In general, the data showing the highest residuals correspond to points situated close to the continental slope.

In conclusion, the different data sets provide compatible information. The residuals corresponding to a particular data set do not grow systematically when another data set comes in and there is no correlation between the peaks in the residuals. The spatial resolution of our model appears to be lower, at times, than the resolution provided locally by some of the data. Increasing both the vertical and horizontal resolution would certainly help satisfying those data more closely, but away from the measurement point the statistical confidence on the results would become very low. It is then decided to keep this limited resolution and interpret the results as a spatially smoothed version of the real field.

\section{Thermal Structure Evolution}

\subsection{Time Series of Vertical Profiles}

The temperature field and corresponding error can be reconstructed at any point of the observed volume from December 15 to April 25. Time series of vertical profiles, for different locations within the Gulf of Lion, provide a good overview of the time and space variability. Four characteristic points are presented in Plate 1: they correspond to mooring position and so provide the best data coverage over the whole period. The profiles combine all the available information and represent the expression of the temperature field at the given points for scales above our $5 \mathrm{~km}$ resolution. T1 represents the eastern boundary condition and in particular the inflow of North Mediterranean Current (NMC) carrying the LIW. T3 at the south boundary links the Gulf of Lion to the interior Mediterranean. T6 $\left(42^{\circ} \mathrm{N}-5^{\circ} \mathrm{E}\right)$ is the central point where convection has been most frequently observed. T5 is also typical of the convection area but more confined by the bathymetry. The profiles displayed are limited to $1800 \mathrm{~m}$ because deeper layers are not altered during that winter (only a few points show penetration of the mixing down to this depth).

At the beginning of the experiment, $\mathrm{T} 1$ displays the strongest positive temperature anomaly of LIW; this signal is associated to the NMC. The time series shows a regular vertical penetration of the cooling from the surface, reaching the LIW level around February 2. The strongest cooling event occurs on February 12, mixing the water down to $600 \mathrm{~m}$. Within a few days, LIW, characterized by a warm temperature anomaly, is supplied but in a diluted form, initiating the restratification of the layer centered around $300 \mathrm{~m}$. Warm surface water comes in at a slower rate and is cooled again between March 26 and April 5. The deepening of the 12.82 isotherm, starting at mid January, preceeds the surface cooling and erosion of LIW. This may correspond to advection of already mixed water from the Ligurian Sea.

Initially, point T3 has the lowest percentage of LIW. A deep mixed layer reaching $1500 \mathrm{~m}$ is clearly seen around March 4. As at T1, some LIW returns in a few days, but the underlying vertical stratification remains weak until the end of the experiment. The evolution of temperature in the surface layers at $\mathrm{T} 1$ and T3 is similar in the longer timescales (correlated with surface forcing) but shows important differences in the high frequencies. Intense cold events occur at T3 (see in particular February 2), produced by a more efficient local cooling or horizontal advection.

The initial vertical structure at $\mathrm{T} 6$ is intermediate between that of T1 and T3. The surface layer stratification is rapidly eroded, and the cooling reaches the LIW layer which has almost disappeared by January 28 . A well-mixed column of water appears on February 23. It is recapped by warm surface water in a few days. The first $150 \mathrm{~m}$ are restratified by February 29 . The LIW returns progressively reaching a significant level only on April 10; simultaneously the deep stratification returns to its initial level. The amount of warm surface water returning over $\mathrm{T} 6$ after the deep mixing event is larger than at T1, excluding the NMC as a possible source for this water.

Point T5 is in the Northwest corner of the convection area. This point was not well sampled during the MEDOC cruises. The time evolution of the vertical structure of temperature here is quite different from the evolution at point $T 6$. The surface layers experience the strongest cooling episodes observed during that winter at the beginning and end of January. Despite this strong local heat loss, deep convection is delayed by several days with respect to the central area: While deep convection occurs at T6 on February 23, at T5 the preconditioned profile seen from the beginning of February is replaced by a column of well-stratified water, probably brought by advection, which remains a few days. In consequence the deeply mixed water column is seen only after February 26, and it is, at the beginning, covered by a warm water pool. We see no open deep convection at T5 as we do at T6; here the mixed water seems to enter progressively from February 26 to March 26 . In contrast with $\mathrm{T} 6$, which restratifies progressively, the 

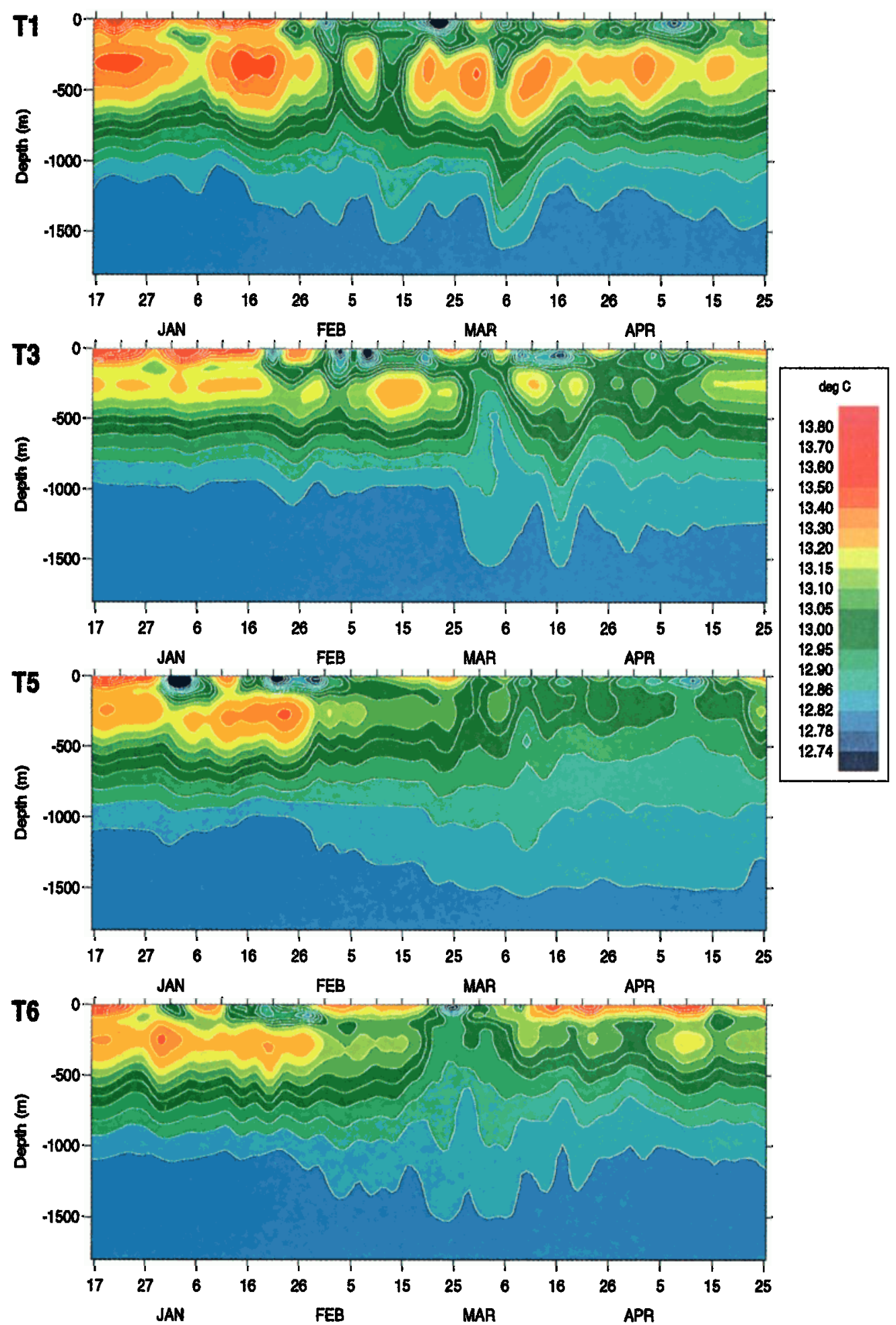

Plate 1. Time evolution of the vertical potential temperature profile estimated by the model at points $\mathrm{T} 1, \mathrm{~T} 3, \mathrm{~T} 5$, and $\mathrm{T} 6$.

profile at $\mathrm{T} 5$ remains mixed and the mixing is even reinforced by the late cooling from March 26 to April 5 . The restratification only starts at the very end of the experiment.

The time series of vertical profiles show a development of convection and restratification similar to what was seen in the time series reconstructed with the MEDOC hydrographic data [Stommel, 1972]. The general evolution follows the surface forcing, and by the end of January the LIW layer is eroded over most of the observed area, even at point T1. Another feature common to the time series presented is a timescales of $\simeq 10$ days, typical of mesoscale activity. With this analysis we enhance the contrast between the different points 
of the convection area, revealing the early deep cooling at $\mathrm{T} 1$, the surface capping at $\mathbf{T} 6$, and the late vertical homogeneization at T5. Although the three phases of preconditioning, violent mixing, and restratification are identified, they are not clearly separated in time and not synchronous at all points. The background general circulation and mesoscale field modifies the vertical nature of convection by redistributing the properties.

\subsection{Horizontal Fields}

The evolution of the temperature profile (Plate 1) at the individual points presented above is better understood by looking at the horizontal fields which relate the different points of the Gulf of Lion. We compute averages of the potential temperature over three layers, each representative of a water mass. At the top is the surface layer $(0-60 \mathrm{~m})$, then the LIW layer $(160-$ $560 \mathrm{~m}$ ), and finally the Western Mediterranean Deep Water $(1000-1500 \mathrm{~m})$. The potential temperature for each of these layers is shown in Plates $2 a, 2 b, 2 c$. The periods correspond approximately to the three phases of convection.

The bottom maps (Plates 2a, 2b, 2c) represent the $a$ posteriori variance as a percentage of the a priori variance, as done in objective analysis. Reference to these maps is particularly important given the irregular distribution of data in space and time. It can be noticed that when no data are available, the field returns to the climatology; conversely, strong features in the estimation occur only where and when detected by the data set, within the limits of the resolution. The differences in the data set spectral windows are revealed by looking at the error maps when one data set only enters in the estimation. For instance, the local effect of the temperature recording appears on the February 2 map (except for the T3-T6 tomography pair, they were the only data). From March 21 to April 10, tomography and $T$ sensors are the only data sets: tomography provides a wide area coverage, but resolution is weak along the long distances (T1-T5). CTD coverage is illustrated by the map of April 25: wide areas are left unexplored.

Two horizontal scales can be identified in the maps: a large-scale field, associated with the surface forcing in the surface layer and with the general circulation at deepest level (illustrated by the tongue of LIW), over which are superimposed smaller-scale structures. Despite the uneven distribution of data and the very different dynamics along the duration of the experiment, the typical radius of this mesoscale is $15-20 \mathrm{~km}$. This is larger than the cutoff length scale $(5 \mathrm{~km})$ and Rossby radius $(5.7 \mathrm{~km})$, which brings up the question: is this scale typical of the field or does it correspond to the resolution of our observational array? Arguments in favor of the first solution are (1) at times March 5 and 9 , the CTD array allows a better resolution but the field does not show 5-km scales, and (2) three float trajectories available from the beginning of March to mid-April describe loops of 10-20 km radius (J.-C. Gascard, personal communication, 1995).
3.2.1. Preconditioning. Plate 2 a corresponds to the preconditioning period (December and January). Temperature is an indicator for the penetration of surface cooling: as long as mixing remains in layer 1 , cooling decreases the temperature along a line with constant $d T / d S$ slope [Swallow and Caston, 1973]. Once mixing reaches layer 2 , the warm and salty LIW is incorporated into the surface layer and the temperature tendency in layer 1 depends on the relative influence of cooling and mixing, while the temperature in layer 2 decreases clearly.

The surface layer experiences a spatially non-uniform cooling. At the beginning (December 18) the surface water is colder in the eastern part of the gulf, then a zonal band of cold water develops and widens (January 1 to 17), and a colder zone builds up in the northwest corner. By January 23 the temperature observed in the northwest reaches its lowest value. The eastern part has already warmed up, by mixing with the underlying LIW. By February 2, the very cold area in the northwest has warmed up, either by vertical mixing or horizontal advection. The later possibility is suggested by the occurence of a very cold surface event seen at T3 (in the south) which seems to come from the north. This direction of advection is confirmed by the current meter measurements. The shallowest current meters available are situated at $350 \mathrm{~m}$ for $\mathrm{T} 5$ and at $90 \mathrm{~m}$ for T3. These depths are not in the surface layer but the current in the Gulf of Lion is strongly barotropic. The direction of the current can then be extrapolated to the surface where its intensity is probably stronger. Figure 5 shows the integrated hodographs of both current meters. It appears that during the first period (January 20 to 25 ), current at T5 points toward the east/southeast, advecting water toward the central area. At T3 the current points toward the south: this point receives the water from the central area. Given the current intensity, some water originating from the cold anomaly in T5 may have traveled to T3 in 10 days.

In the LIW layer the maximum temperature is found initially in the northeast corner, along the path of the NMC. The LIW enters the area by this corner and fills the Gulf of Lion. Temperature starts to decrease over the whole area by January 17-23. The largest temperature decrease is observed in the northeast where a very cold event, happening on February 2 at T1, brings water colder than the water produced inside the area by mixing with the above water. The water entering at this corner may result from mixing which has taken place upstream, in the Ligurian Sea, a region where convection can also occur. In the south, the cooling is slower and a stationary blob of LIW stays in place for 30 days. Because of inadequate sampling, the exact shape of this blob and possible connection with the outside are difficult to define. Despite strong surface cooling at T5 the deficit in temperature at LIW level is stronger at T6. As in the surface layer, the cooled water masses have been redistributed. During the preconditioning period shown, the evolution in the deep layer is very slow and we see mostly weak mesoscale activity. There seems to 


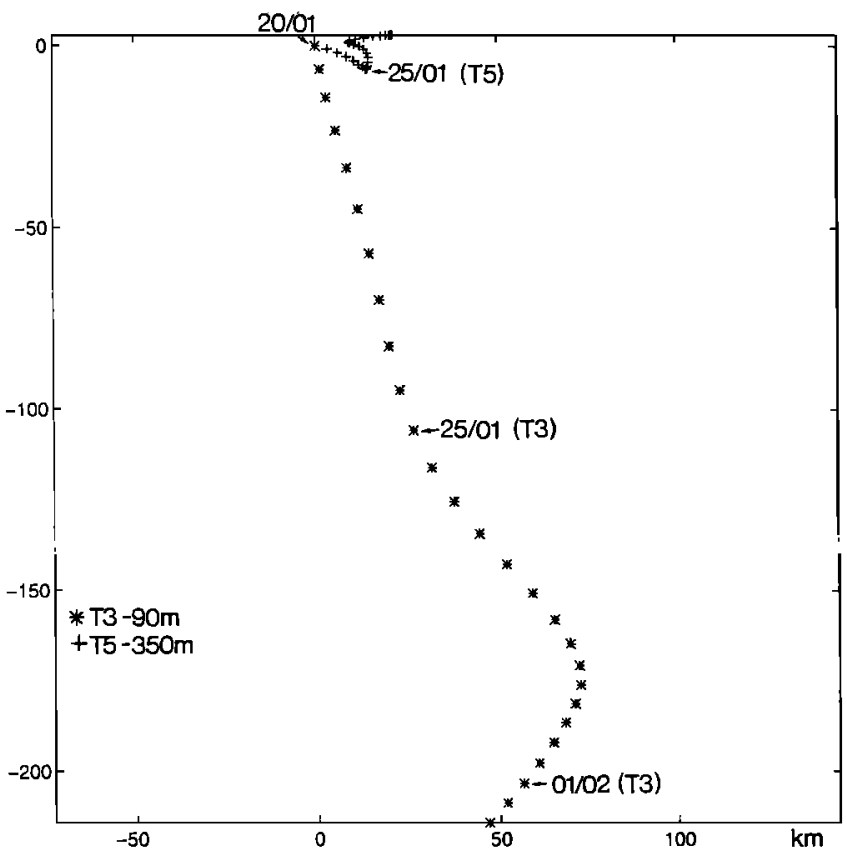

Figure 5. Integrated hodograph, between January 20 and February 2, for the current at T3 $(90 \mathrm{~m})$ and T5 $(350 \mathrm{~m})$. It shows the eastward transport at $\mathrm{T} 5$ and southward transport at T3.

be a slight warming (barely $0.01^{\circ} \mathrm{C}$ ) progressing from the east toward the central area.

The large-scale view of the preconditioning leading to convection is that it results from a locally intensified surface forcing, applied on an area where the water masses are confined by the general circulation. From our observations it appears that the process is more complicated and that the effect of spatial variability cannot be neglected for its understanding or when doing heat budgets. Two scales play an equally important role during the preconditioning.

(1) The water masses cooled by the atmospheric forcing are redistributed in the Gulf of Lion during the preconditioning phase. This makes it difficult to predict from the surface layers maps the exact place where convection is likely to start. These mesoscale horizontal processes may correspond to the instabilities predicted by the two-layer model of Gascard [1978].

(2) The area is not totally isolated from the rest of the basin. The entrance conditions are modified during the preconditioning by mixing which has taken place outside the area. On the other hand, cold water may be exported, slowing down the preconditioning process. The general circulation is an important element of the final budget.

3.2.2. Convection. During preconditioning, cooling has modified the upper $1000 \mathrm{~m}$ (surface and LIW layers), but there is no evidence of complete vertical mixing as it is described by mixed layer models: a weak temperature stratification remains. As the surface cooling is maintained throughout winter, a threshold is reached and the first deep convection chimneys are observed around February 21 (Plate 2a and 2b). The main chimney is centered slightly east of the canon- ical point $42^{\circ} \mathrm{N}-5^{\circ} \mathrm{E}$ surrounded by smaller chimneys in the west and northwest. The area affected by deep convection extends until March 4 by the development of new patches at the periphery. The resulting convection patch appears distorted by the same horizontal scales observed during preconditioning (15-km radius). The observed chimneys show a columnar structure down to $1500-1700 \mathrm{~m}$, more or less capped with warmer water. In the horizontal maps the convective chimneys are characterized by a low potential temperature at the LIW level $(\theta<13.00)$ and relatively high potential temperature at the deep level $(\theta>12.83)$. The anomalies relative to the mean stratified profile are at least $-0.20^{\circ} \mathrm{C}$ and $+0.03^{\circ} \mathrm{C}$, respectively, for the LIW and deep layers. The horizontal maps of these two layers are anticorrelated. In the surface layer, horizontal advection has redistributed the properties and the convected areas are difficult to detect.

In the Gulf of Lion convection occurs progressively and is influenced by the initial stratification and the background circulation. It starts at locations where the vertical structure is favorable, such as cyclonic eddies which bring weak vertical gradients, and so takes the horizontal scale of the preexisting field. As the forcing goes on, more areas meet this low gradient criterion and the number and size of chimneys increase. The final size of the convection patch is that of the mean preconditioned area.

Our observations of the development of convection differ significantly from the nonhydrostatic modeling of Jones and Marshall [1993] and Send and Marshall [1995]. While, in the model, the water is initially horizontally homogeneous and at rest; in our observations the background field has its own spatial structure and currents. The preexisting mesoscale influences the scale of the chimney. In the model, the chimney takes the exact shape of the forcing and mesoscales appear only when the chimney becomes baroclinically unstable. A second important difference lies is in the forcing. In the Gulf of Lion the forcing varies in time and barely reaches $300 \mathrm{~W} \mathrm{~m}^{-2}$ when averaged over 5 days. In the numerical experiment a strong circular forcing of $800 \mathrm{~W} \mathrm{~m}^{-2}$ is applied continuously during 6 days. Madec et al. [1991a] have studied the relative contribution of vertical convection and horizontal mixing in a primitive equation model by comparing a purely vertical run to regular three dimensional experiments. They noticed that the horizontal processes slow down the vertical convection. Another experiment, at higher resolution, compared the effect of a mean cooling applied continuously to an intermittent more intense cooling, but with the same mean value. Madec et al. [1991b] showed that intense cooling inhibited the horizontal advection and was more efficient for producing convection. Send and Marshall's [1995] experiment then appears as an extreme case. At the other extreme is Herbault's [1995] attempt to model realistically the western Mediterranean circulation. Despite the use of a daily wind forcing, this model is not able to reproduce convection with the correct rate. A number of problems are still to be solved. 
3.2.3. Restratification. During the convection period, vertical mixing dominates. In the following period the volume of convected water adjusts to a new equilibrium through the two processes of sinking and spreading. The newly formed water tends to sink toward its equilibrium depth defined by the density of the mixed column ( $1500 \mathrm{~m}$ during that winter) but is maintained by the horizontal currents through geostrophic adjustment. Advection by the background circulation and associated mesoscale field or by baroclinic instability of the convective chimney produces horizontal transport or spreading at a level shallower than the equilibrium depth. The relative effect of the two processes in competition determines the amount of heat and mass transfered to the deep layers.

In the Gulf of Lion, at the end of the THETIS 1 convective period, the water above $750 \mathrm{~m}$ is anomalously cold, while it is anomalously warm between 750 and $1500 \mathrm{~m}$, with respect to the initial temperature profile. The same contrast exists in space: the historical data compiled by Brasseur et al. [1994] show that the surface layer in the Gulf of Lion is anomalously cold with respect to the rest of the western basin. At the shallow levels at least, a pool of warm water is then available close to the convection area, for mixing with the cold water. At depth, the anomalously warm water, in density balance at the base of the mixed water column, will spread horizontally into the deep Mediterranean basin, providing a mechanism for deep water temperature increase.

The horizontal maps shown in Plate 2a-2c give some idea of the timescale on which the exchanges take place. We observe in the days following convection a period of rapid evolution: the surface capping already started during convection continues; at level 2, warm water appears at the eastern boundary after March 9 and the convected area is globally displaced toward the northwest.

The rapid adjustment is followed by a phase of slower evolution (from March 21). The surface layer warms up continuously over the whole area. This warming is not explained by the local atmospheric warming, which starts only in April (Figure 6), but results from advection of warmer waters from outside the Gulf. The southernmost point (T3) seems to receive the water cooled in the Gulf of Lion in agreement with the mean current direction observed in the current meter recordings. The warming is interrrupted by a short cooling episode resulting from an increased heat loss to the atmosphere occurring between days March 26 and April 5 .

In layer 2 the LIW entering from the southeast nearly reaches the central point $42^{\circ} \mathrm{N}-5^{\circ} \mathrm{E}$; at that time the LIW water layer there is thicker than it has been at any other time of the experiment. The amount of LIW entering the northeast corner is still very weak, suggesting a change in the general circulation pattern of this water mass. The secondary cooling event reaches layer 2 in the north and is responsible for the reopening of the chimney in the northwest corner (T5).

In the deep layer, the path of the convected water is hard to track. The water mass initially in the center seems to migrate toward the northwest corner, while some of it may escape through the southern and western side (this part of the array is poorly instrumented). The general increase of temperature within the Gulf of Lion relative to initial conditions indicates that mixing is taking place within the convection area.

At the end of the experiment (April 25), the stratification inside the Gulf of Lion is not restored to its initial conditions. The final structure is characterized by a weakened vertical gradient of temperature with a deficit in LIW and an increased deep water temperature $\left(0.01^{\circ}\right.$ to $\left.0.02{ }^{\circ} \mathrm{C}\right)$.

\section{Buoyancy and Heat Budgets}

The temperature evolution presented above is better understood when related to the atmospheric forcing and buoyancy budgets, which trigger and control the vertical mixing. Without resorting to a full surface forced numerical model of the region, which is beyond the scope of the present study, the simplest mixed layer model is used to evaluate whether surface fluxes can account for the observed changes in upper ocean stratification and the onset of convection, to assess the importance of advection, and to determine to what extent the spatial variability of the initial density field and of the forcing field can account for the location of the convective event.

\subsection{Mixed Layer Model and Buoyancy Budgets}

If at some time there exists a mixed layer (with uniform density, temperature, and salinity) of depth $h(t)$, a surface buoyancy flux $Q_{B}$ acting for a time step $d t$ gives a density increase: $d \rho=(g h)^{-1} Q_{B} d t$. This creates an instability which induces mixing and deepening of the mixed layer to a new depth $h(t)+d h$. Assuming the mixing to be nonpenetrative, continuity of density at the base of the mixed layer, where the density profile is $\rho(z)$, requires $d \rho=\rho^{\prime}(h) d h$. Eliminating $d \rho$ between the two expressions gives the implicit relation for the evolution of $h(t)$ :

$$
Q_{B} d t=g h \rho^{\prime}(h) d h,
$$

which integrates to

$$
\int_{0}^{t} Q_{B} d t=g \int_{0}^{h}[\rho(h)-\rho(z)] d z \equiv \Phi(h) .
$$

Not surprisingly, the importance of the density gradient $\rho^{\prime}(h)$ appears here: for a given flux increment $Q_{B} d t, d h$ is inversely proportional to $\rho^{\prime}(h)$ (the weakest the stratification, the largest the deepening). The right hand side of (5), $\Phi(h)$, is the integrated buoyancy to depth $h$; it is a measure of the stability of the water column, a weight per unit area [Gill, 1982] expressed in newtons per square meters. (One could alternatively normalize by $\rho_{0}$ to obtain units of (meters per second) ${ }^{2}$. Those units can be obtained by dividing our values by $10^{3}$.) It also represents the buoyancy flux required to mix to depth $h$. 
Once the mixed layer depth has been set by the implicit relation (5), its temperature and salinity can be obtained by expressing conservation of heat and salt, as given by Mertens [1994]. Predictions of $h(t)$ obtained from this simple one-dimensional model are rather sensitive to the initial profiles (which are quite variable, see section 4.3.1 and Figure 8), to the start time of the simulation, and to the time history of the surface fluxes. Integration of (5) with a density profile of the form $\rho(z)=\rho_{\infty}-\Delta \rho \exp (-z / L)$ or scaling arguments shows that deepening will be large when $\int_{0}^{t} Q_{B} d t \simeq g L \Delta \rho$, i.e., when the surface buoyancy $(g L \Delta \rho)$ is removed.

Considering the average density profile from Suroit 1 cruise, for those stations in the central area (defined as the shaded area of Figure 1), a good fit is obtained with $\rho_{\infty}=29.100, \Delta \rho=0.49 \mathrm{~kg} \mathrm{~m}^{-3}$, and $L=80 \mathrm{~m}$, while a fit on the average of all the Suroit 1 stations, which include more stratified profiles, gives $\Delta \rho=0.60 \mathrm{~kg} \mathrm{~m}^{-3}$ and $L=90 \mathrm{~m}$. Correspondingly, for the central area, $g L \Delta \rho=383 \mathrm{~N} \mathrm{~m}^{-2}$, while for all the stations, $g L \Delta \rho$ $=528 \mathrm{~N} \mathrm{~m}^{-2}$. The significant difference between those two fits is an indication of the heterogeneity of the area.

The critical values of 383 and $528 \mathrm{~N} \mathrm{~m}^{-2}$ are reached on January 21 and February 14 (Figure 6), respectively. While the second date is close to that at which convection is observed to occur, but over a limited area, in late January, convection is not observed to have penetrated
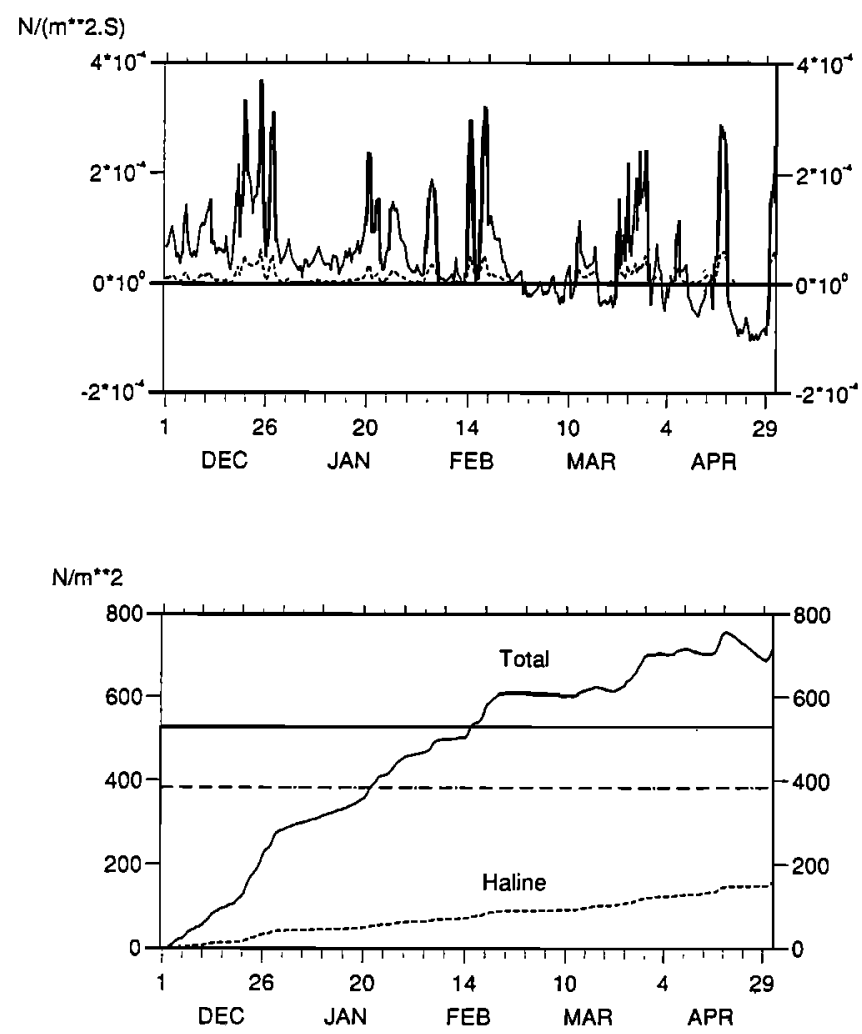

Figure 6. (top) Total buoyancy flux time series at $42^{\circ} \mathrm{N}, 5^{\circ} \mathrm{E}$, with the contribution of the haline flux shown as dashed. (bottom) The corresponding cumulative values; horizontal lines are drawn at the values 383 and $528 \mathrm{~N} \mathrm{~m}^{-2}$ (dashed-dotted and solid lines respectively). to any great depth. With this simple model, the surface forcing data would predict deep convection to occur sooner, deeper, and over a wider area than what is observed. Nonetheless this analytical example illustrates the rapid deepening that occurs when $\int_{0}^{t} Q_{B} d t \simeq g L \Delta \rho$. It gives qualitative estimates of the depth reached at a certain time or of the time at which a given depth will be reached. Associated errors can be estimated if a constant bias $\delta Q_{B}$ is assumed on the buoyancy flux (see Appendix B). A simple error analysis shows that the time of occurence of deep convection can be predicted with a better accuracy (Figure 6) than the final depth of the mixed layer. The latter is a sensitive function of the deep density gradient, which is quite small at depth.

\subsection{The Surface Fluxes}

4.2.1. The data. The net heat flux at the ocean surface can be computed as

$$
Q_{h l}=Q_{l}+Q_{h}+Q_{s}+Q_{b} .
$$

where $Q_{h}$ and $Q_{\ell}$ are the sensible and latent heat fluxes, $Q_{s}$ is the short wave radiation, and $Q_{b}$ the long wave radiation. The different terms of the surface fluxes are obtained from Météo France. They are the output of the operational meteorological forecast model Péridot. An error analysis of these data is given in Appendix B; it leads to the conclusion that an uncertainty of \pm 20 $\mathrm{W} \mathrm{m}^{-2}$ must be attached to estimates of $Q_{h l}$.

Convection is driven by hydrostatic instability, i.e., by the surface buoyancy flux, which is given by Gill [1982] as the sum of a thermal $\left(Q_{B h}\right)$ and a haline terms $\left(Q_{B e}\right)$ :

$$
Q_{B}=\left(g \alpha / c_{w}\right) Q_{h l}+\left(g \beta S_{s} / L_{v}\right) Q_{\ell}=Q_{B h}+Q_{B e} .
$$

The constants have the following values: specific heat of water, $c_{w}=3.97 \times 10^{3} \mathrm{~J}(\mathrm{~kg} \mathrm{~K})^{-1}$; the thermal expansion coefficient of seawater $\alpha=2 \times 10^{-4} \mathrm{~K}^{-1}$, the corresponding coefficient for salinity, $\beta=\rho^{-1} \partial \rho / \partial S=$ $7.75 \times 10^{-4}$, the latent heat of vaporization, $L_{v}=2.45 \times$ $10^{6} \mathrm{~J} \mathrm{~kg}^{-1}$, and sea surface salinity $S_{s}=38.4 \mathrm{psu}$. Precipitation effects cannot be included since we have no information on them. It is shown in Appendix B that they have a small effect.

Figure 6 shows the time series of buoyancy flux and the integrated fluxes (left-hand side of (5)) at $42^{\circ} \mathrm{N}$, $5^{\circ} \mathrm{E}$, with the haline contribution indicated as a dashed line. Temperature effects contribute most to buoyancy variations; over the first 3 months, $\left\langle Q_{B h}\right\rangle=5.69$ $\left\langle Q_{B e}\right\rangle$, so that at the end of the series the relative cumulative effects are in the same ratio. Although the heat contribution dominates the surface buoyancy flux, the salt content in the water column plays an essential role in defining its stability. Indeed, Mertens [1994] shows that a mixed layer simulation which includes freshwater fluxes yields a final depth $1000 \mathrm{~m}$ larger than a run driven only by heat fluxes.

4.2.2. Surface flux variability. The data show strong time and moderate spatial variability. In order 


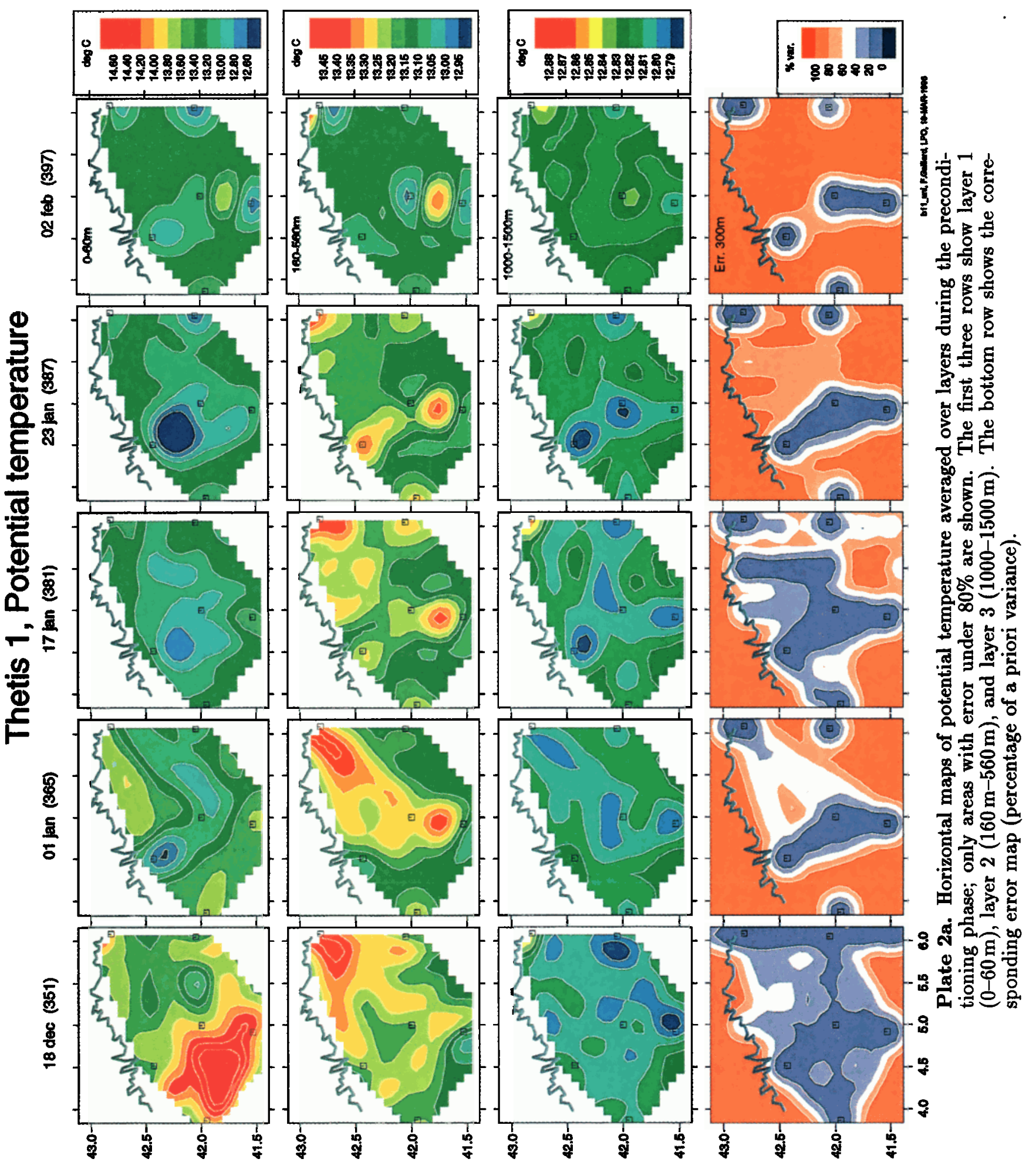



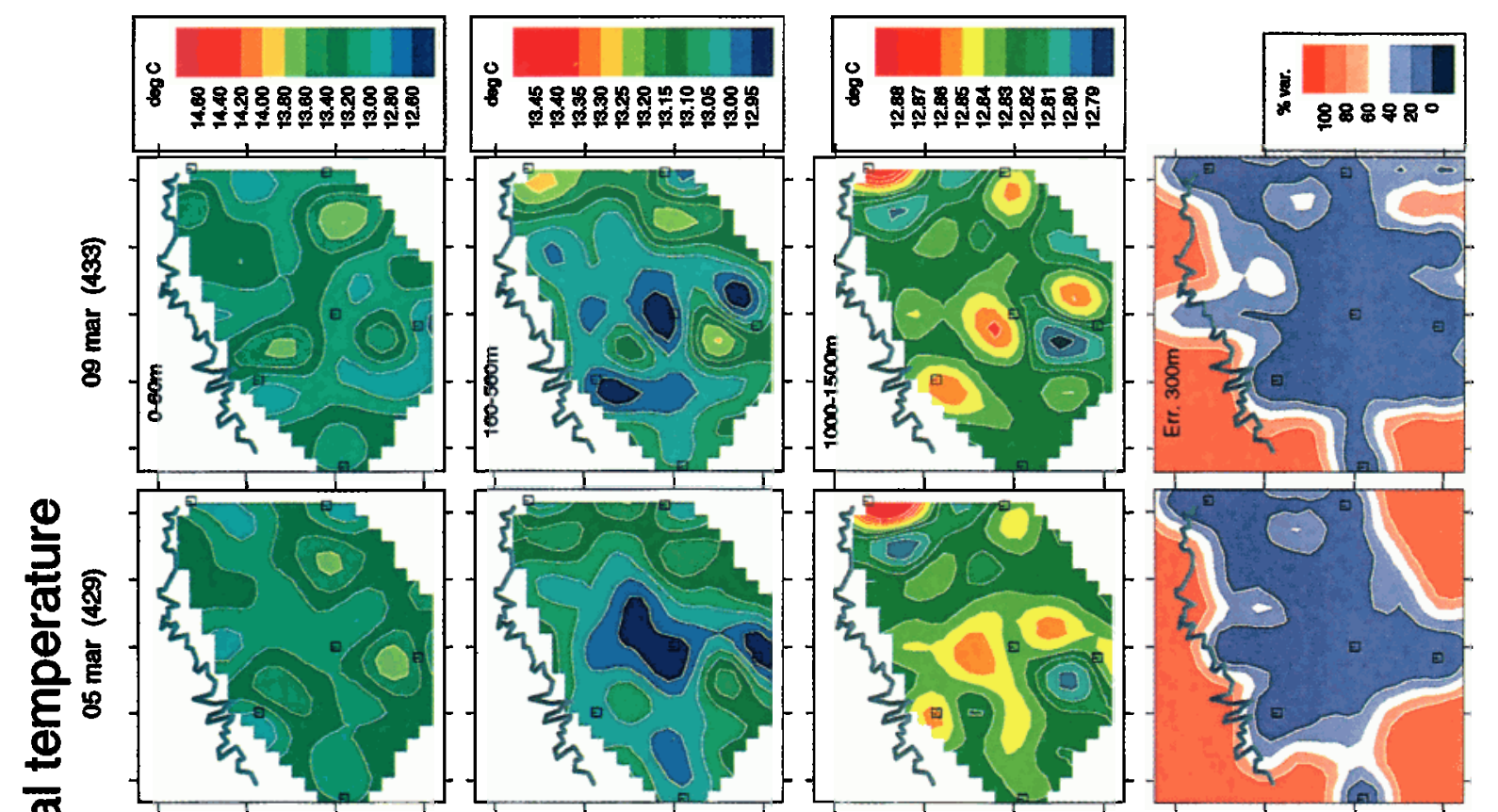

号
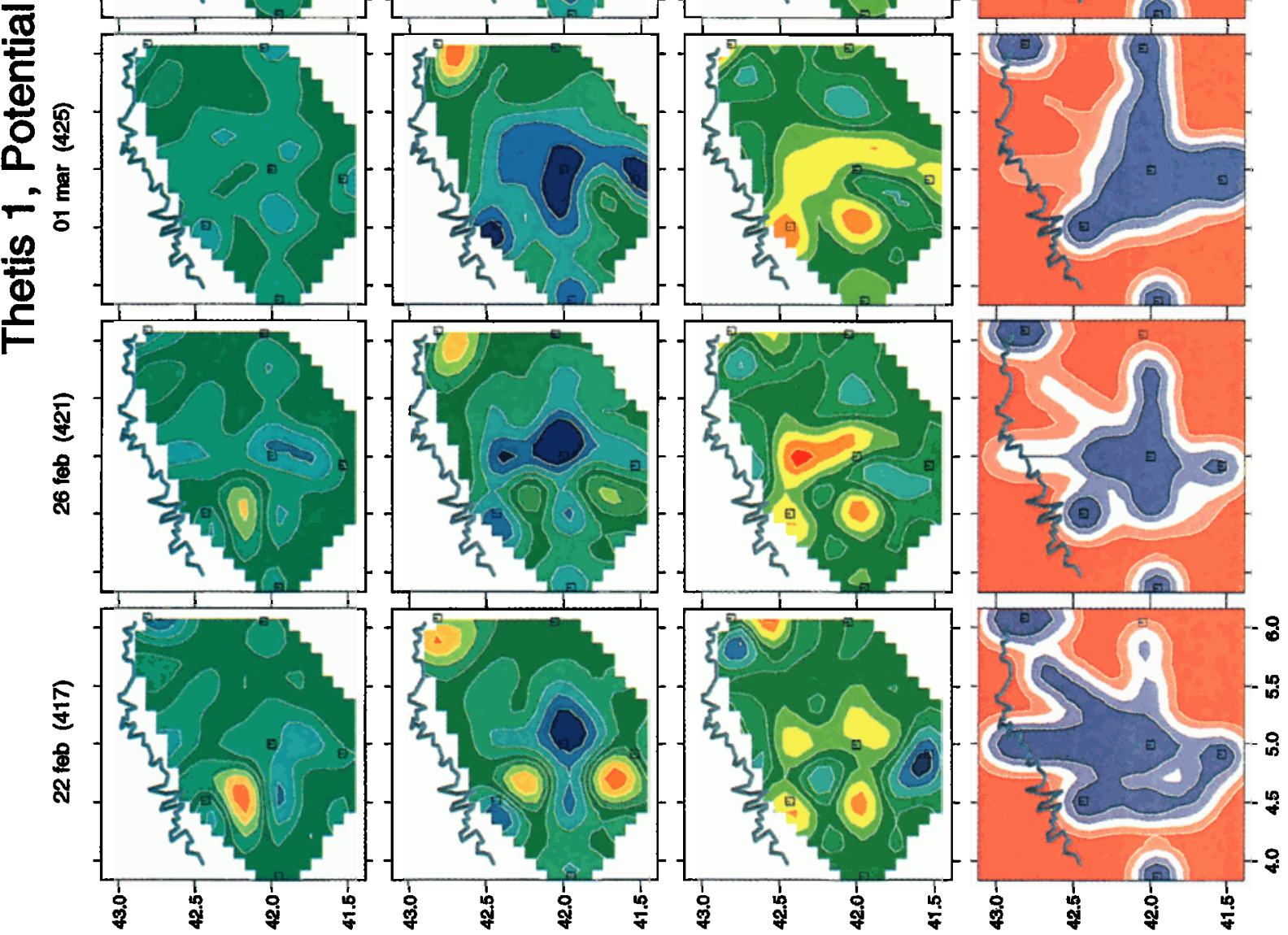

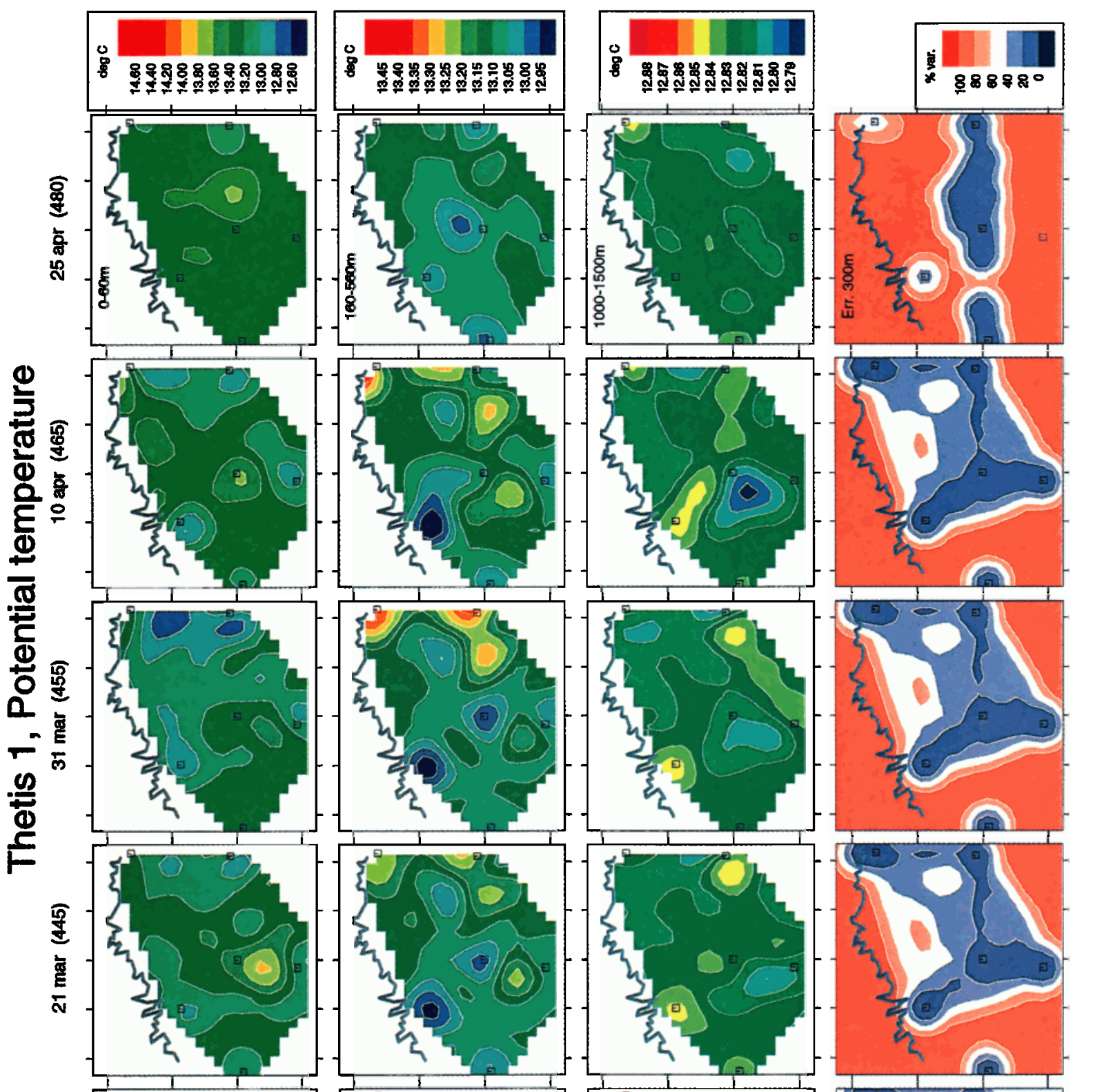

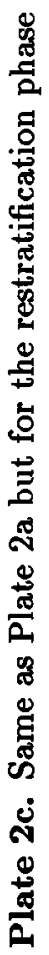
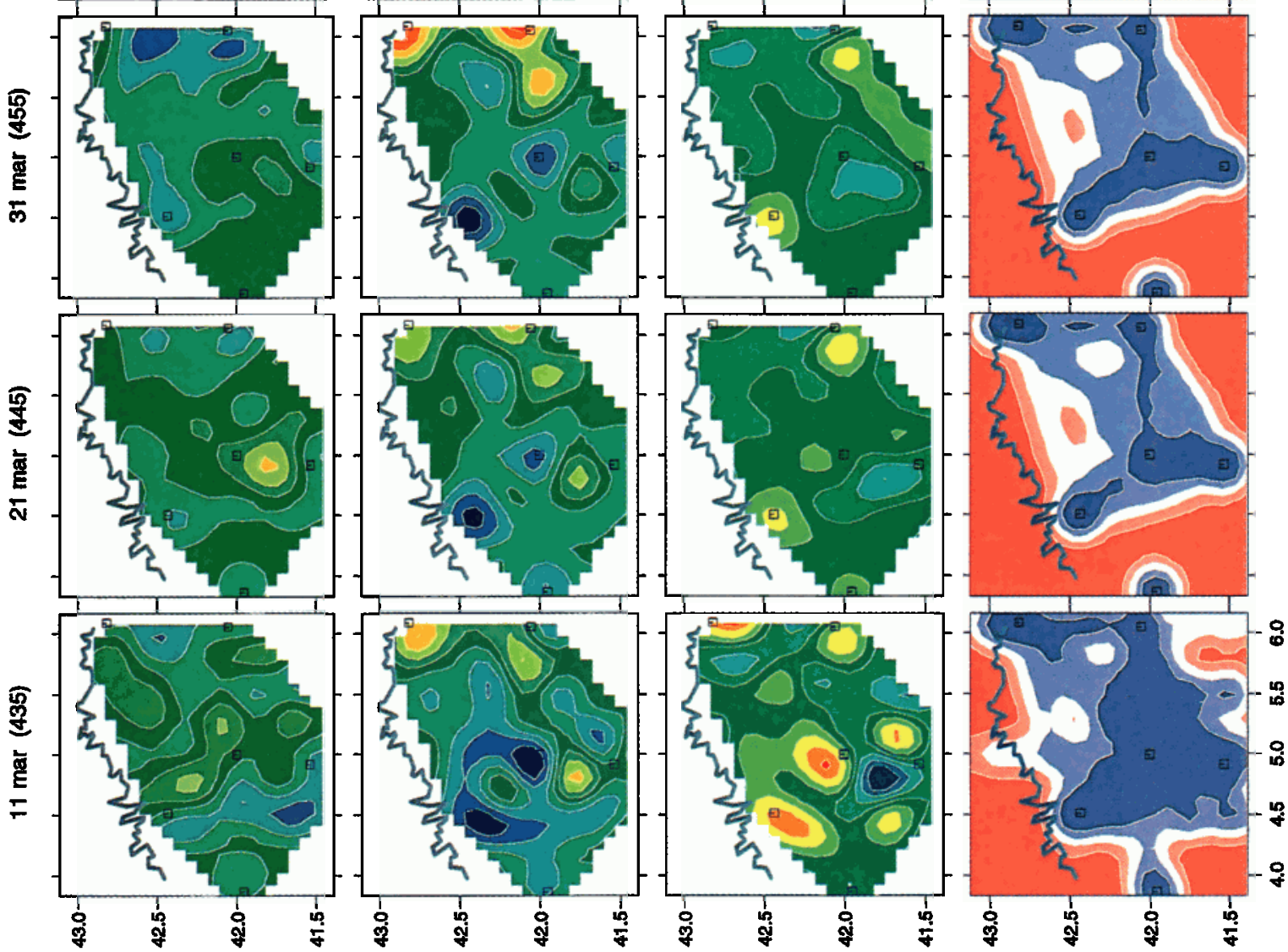

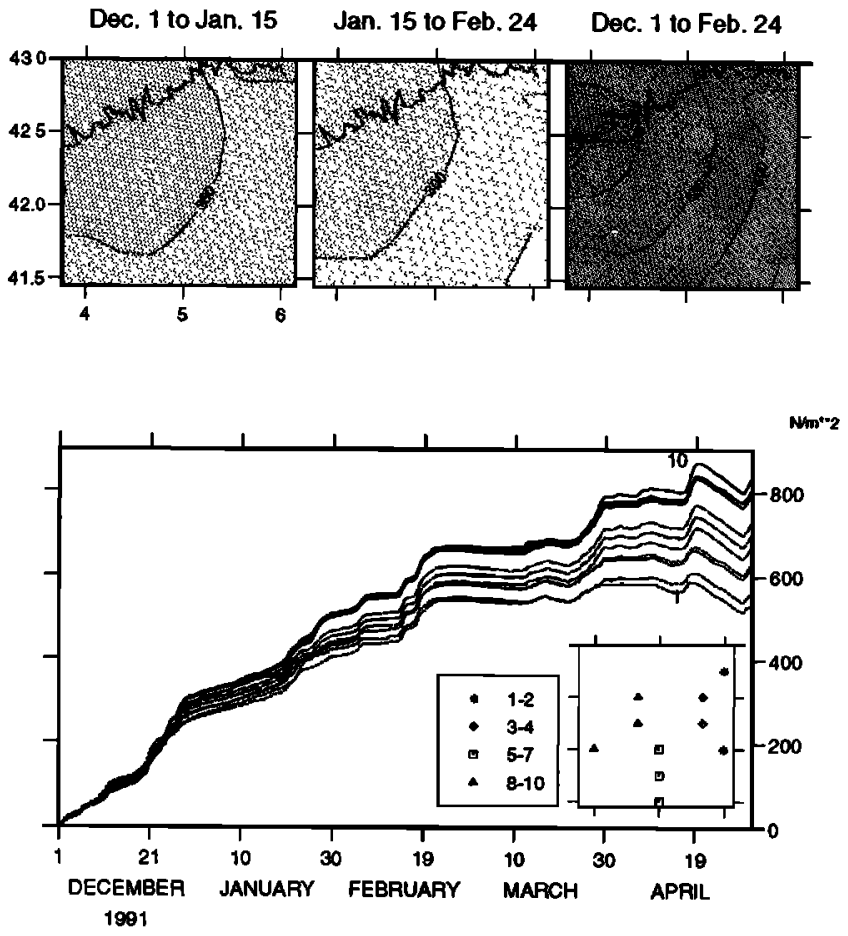

Figure 7. Surface buoyancy loss from the Péridot analysis (in newtons per square meter). (top) Maps of the cumulative losses for the periods corresponding to the CTD cruises. (bottom) Time evolution of buoyancy losses at 10 selected points. The positions of the points are marked with symbols. Although the general trend is similar, the levels differ significantly, increasing from east to west.

to compare surface buoyancy fluxes with ocean buoyancy content, three dates are chosen, corresponding to the times of CTD surveys: December 1, January 15, and February 24. Figure 7 shows maps of the surface buoyancy loss, for the intervening periods (December 1 to January 15 , and January 15 to February 24). There is a clear maximum in the western part of the gulf, but the field is fairly uniform, except along the coastlines where high gradients occur. For the three periods considered and over most of the area of interest, the surface fluxes would be able to remove buoyancy of over $350 \pm$ $37,300 \pm 33$, and $650 \pm 71 \mathrm{~N} \mathrm{~m}^{-2}$, respectively.

The time evolution of the losses is illustrated on the bottom panel of Figure 7, where cumulated fluxes at selected points (mooring locations and intermediate points) are plotted as function of time. The general evolution is quite similar, but the accumulated difference increases: on January $15 Q_{B}$ ranges from 300 to 369 ( $\Delta$ $=69)$, on February $24 Q_{B}$ ranges from 543 to $673(\Delta=$ $130)$, and on April $7 Q_{B}$ ranges from 583 to $802(\Delta=$ 219). The largest values occur north of $42^{\circ} \mathrm{N}$ and west of $5^{\circ} \mathrm{E}$.

In summary, the surface fluxes, as given by the Péridot model, appear to be large scale, with similar time evolution over the whole area. The largest values are encountered in the western part of the gulf.

\subsection{Buoyancy in the Upper Layers}

4.3.1. Buoyancy variability in the upper layers. We consider the buoyancy changes in the upper layers in order to relate them to the surface fluxes. The relevant quantity is the function $\Phi(h)$ introduced in (5), which represents the buoyancy required to mix to depth $h$. We use CTD data from Suroît 1 (late November) and Suroit 2 (mid January) to calculate $\Phi(h)$. Figure 8 shows this function for the stations within the central area defined in Figure 1, for the two cruises. There is a remarkably high variability in the stability from station to station, by a factor of 2 (Suroît 1) to 3 (Suroît 2). The initial conditions indicate that a flux of $400 \mathrm{~N} \mathrm{~m}^{-2}$ could mix half the stations to $1000 \mathrm{~m}$, while $300 \mathrm{~N} \mathrm{~m}^{-2}$ could mix all of them to at least $100 \mathrm{~m}$. The spatial distribution of $\Phi(1000)$, shown on Figure 9, exhibits an initial low stability region between $5^{\circ}$ and $6^{\circ} \mathrm{E}$ and a more fragmented pattern in mid January. Both Figures 8 and 9 indicate an overall decrease in stability from December 1 to January 15; averaged over the central stations, the upper $1000 \mathrm{~m}$ have lost $164 \mathrm{~N} \mathrm{~m}^{-2}$ (151 from 0 to $100 \mathrm{~m}, 24$ from 100 to $200 \mathrm{~m}$, with a slight gain of 7 in the LIW, from 200 to $500 \mathrm{~m}$ ). Some of the local changes can be quite large, reaching 300 to 400 $\mathrm{N} \mathrm{m}^{-2}$ in some western locations and even a maximum of $800 \mathrm{~N} \mathrm{~m}^{-2}$ in the coastal current (which has been excluded from the depth averages).

4.3.2. Comparison of fluxes and upper ocean buoyancy changes. During the first 45 days (from December 1 to January 15), the atmospheric fluxes would be able to remove about $350 \pm 37 \mathrm{~N} \mathrm{~m}^{-2}$ over

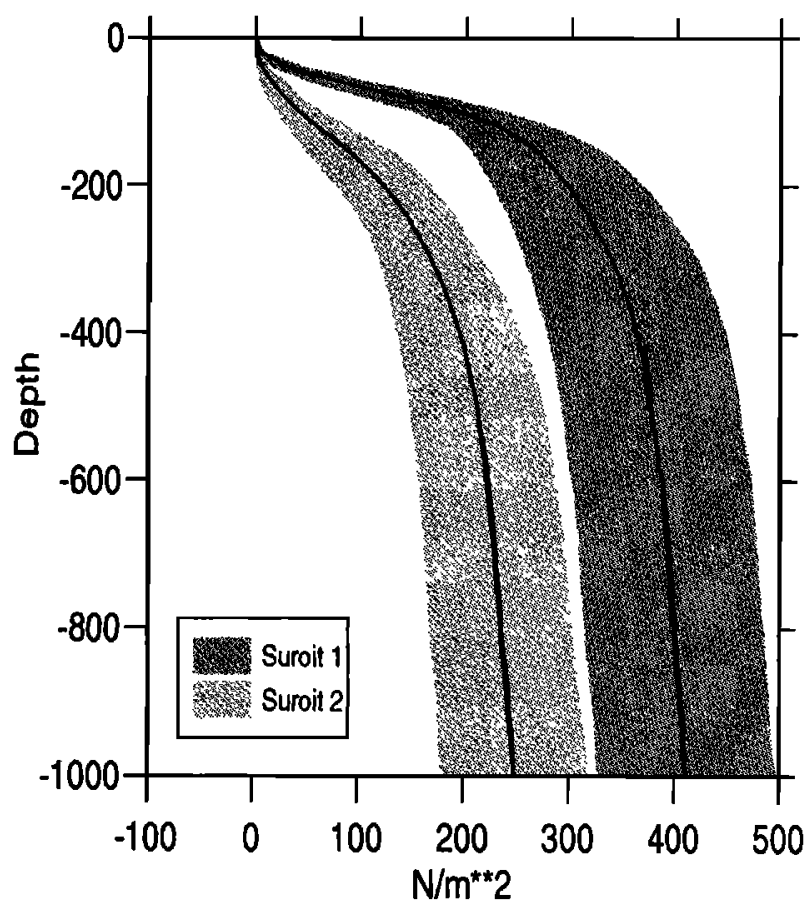

Figure 8. Buoyancy content in the upper $1000 \mathrm{~m}$, for the central area, as calculated from C'TD data (Suroit 1 , early December and Suroit 2, mid January cruises). The curves represent the mean values, and the shaded areas are 1 standard deviation. 

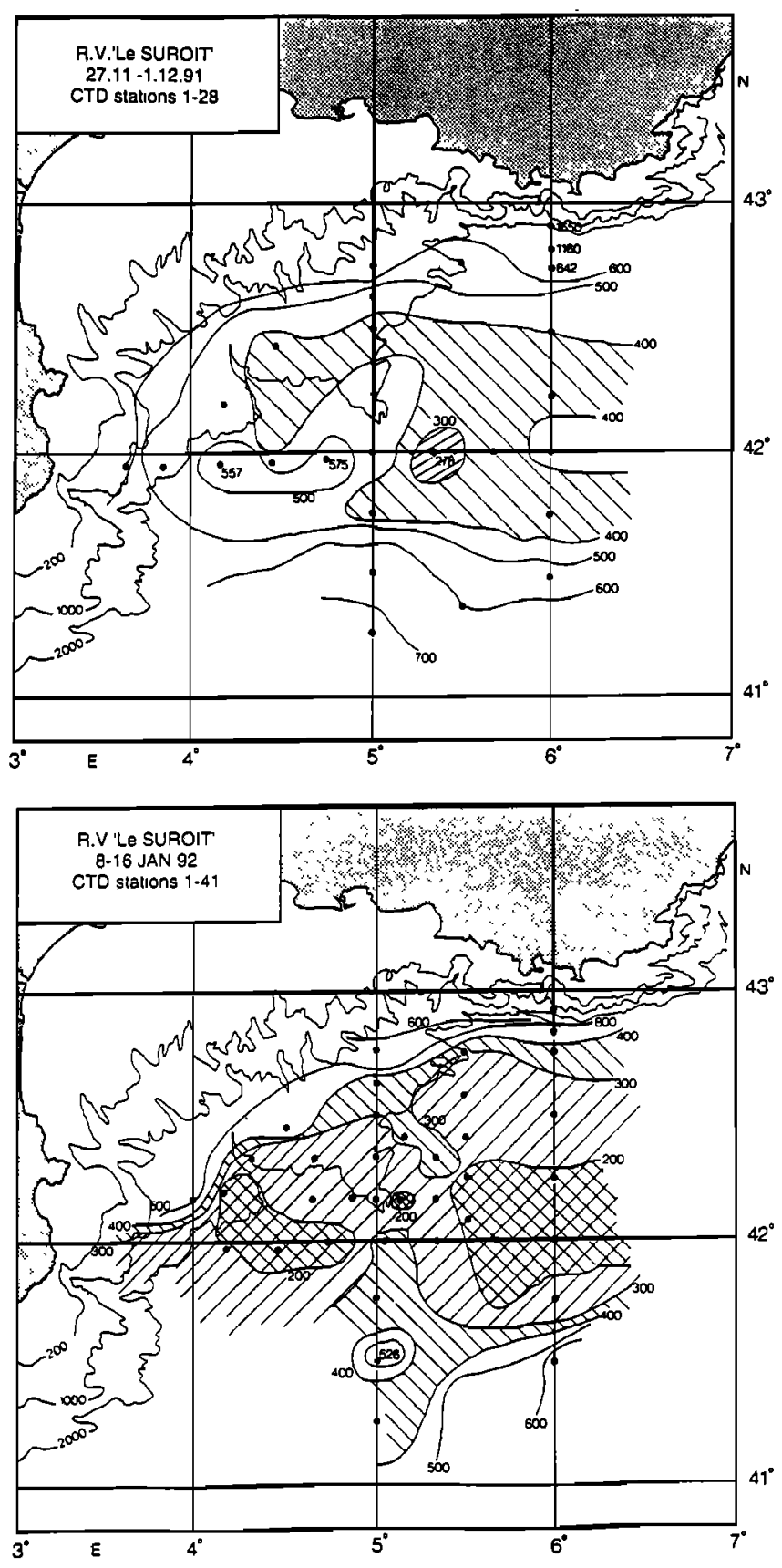

Figure 9. The value of $\Phi(1000)$ (equation (4)), which measures the buoyancy to be removed to mix to $1000 \mathrm{~m}$. (top) Suroit 1 (late November); (bottom) Suroit 2 (mid January).

most of the area (Figure 7). From the initial distribution shown on Figure 9, such fluxes would be able to mix some stations to $1000 \mathrm{~m}$, several to $500 \mathrm{~m}$, and all to $150 \mathrm{~m}$. However, the ocean has lost only $164 \mathrm{~N} \mathrm{~m}^{-2}$, essentially in the upper $200 \mathrm{~m}$, and none of the profiles observed in mid January show any clear evidence of mixed layer development. It must be concluded that the one-dimensional view is too simplistic and that other processes must occur, for which horizontal advection is obviously a prime candidate. The very high buoyancy values observed in the NMC suggest that it might con- tribute some advective buoyancy flux to the gulf. SSGD observed also that up to mid January, the upper ocean was warmer than what might be inferred from surface fluxes.

For the next 40 days (from January 15 to February 25), the buoyancy loss inferred from the surface fluxes is of order $300 \pm 33 \mathrm{~N} \mathrm{~m}^{-2}$, with larger values to the west (Figure 7), which is essentially enough to mix to $1000 \mathrm{~m}$ most of the area shown on Figure 9 (bottom panel). Although deep convection (to $1500 \mathrm{~m}$ ) is observed in mid February, it has a somewhat more limited extent; it is again suggested that horizontal advection must intervene.

\subsection{Volume Heat Budgets}

4.4.1. Computing volume heat budgets. Given the relative importance of the heat transport by mesoscale, any local budget would be difficult to interpret. By performing area averages of the heat gain over the whole area influenced by convection (the central area, named $A_{c}$ ), we reduce the local effect of mesoscales. The mean heat gain relative to the first day of the analysis, $t_{0}=$ December 17 , is computed for each of the previously defined layers as

$$
H_{i}(t)=\int_{h_{\mathrm{i}+1}}^{h_{\mathrm{v}}}\left[T(z, t)-\bar{T}\left(z, t_{0}\right)\right] \rho C_{p} d z
$$

where $H_{i}$ is expressed in joules per square meter and $(\bar{T})$ denotes the temperature averaged over the central area. The corresponding mean heat gain at the surface is computed from the fluxes given by Péridot. From the time evolution of these averaged quantities (Figure 10), we identify three main periods, which correspond approximately to the three phases presented in the horizontal maps (Plates 2a-2c):

(1) From December 17 to January 23, the trend is a rapid loss of heat in the surface layer and slow cooling if the LIW layer, while the deep layer heat content remains unchanged. Strong heat exchange between the two upper layers happened in the form of an event which occurred during the first week of January, resulting in the warming up of the surface layer and cooling of the LIW layer.

(2) The period January 24 to March 5 is characterized by the warming of the deep layer; it includes the deep convection period but starts earlier. The warming of the deep layer occurs in two episodes. During the first episode (last week of January, first of February), the surface layer warms up by exchanging heat with the LIW which cools rapidly. The heat gain by the deep layer is moderate. This is the transition between the preconditioning and deep convection. Convection may have started inside the area but was not resolved by the array. It may also have occurred outside and mixed water advected in. The second episode corresponds to the violent mixing period: the surface layer cools slightly, but there is an intense exchange of heat between LIW layer and the deep layer, cooling the first and warming 

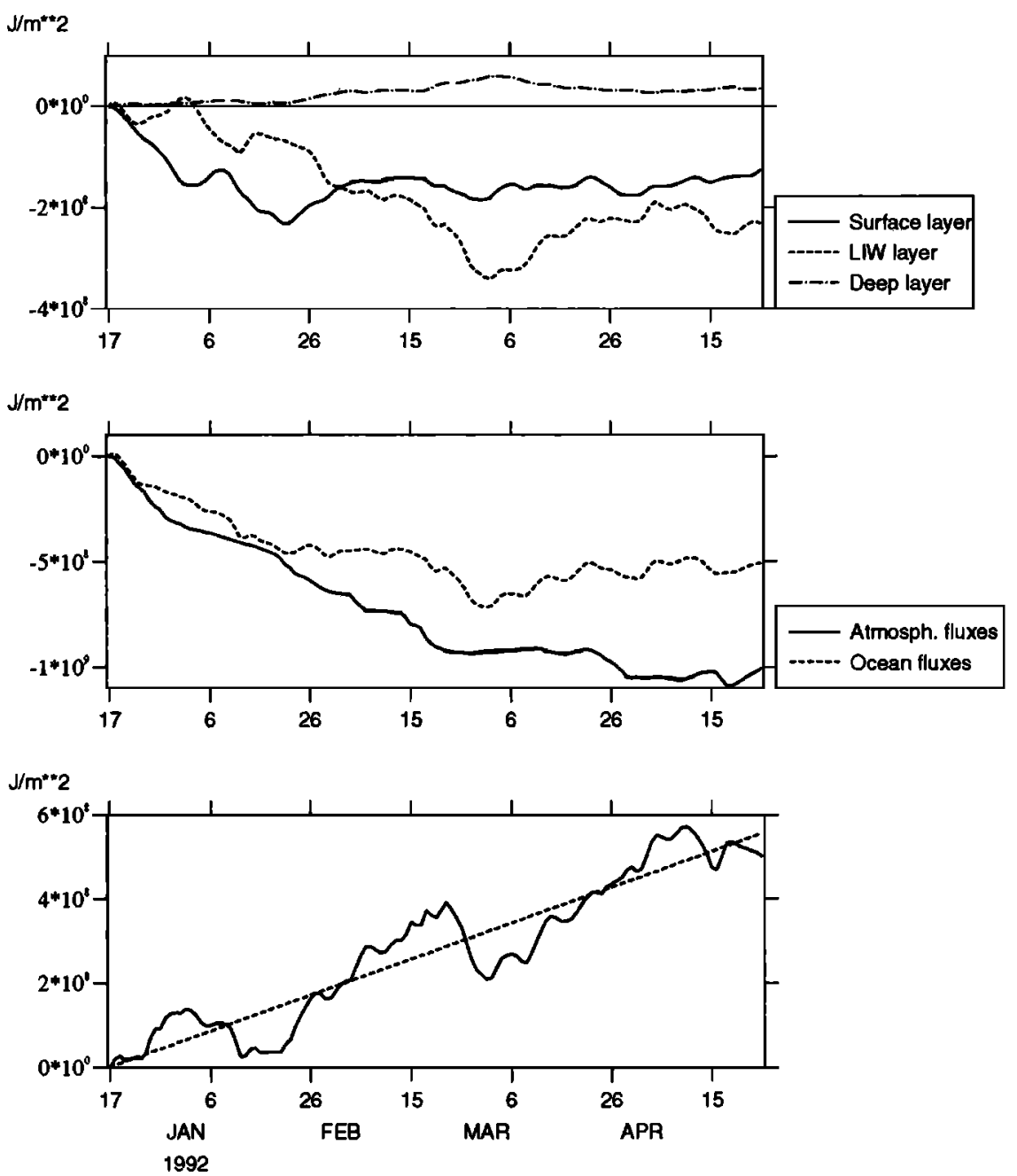

Figure 10. Mean budgets over the central area. (top) Evolution of the heat content in the surface, LIW, and deep layers. (middle) Evolution of heat content from 0 to $1500 \mathrm{~m}$ and of the surface fluxes given by Peridot. (bottom) Heat deficit in the central area (difference between the two previous curves; solid curve) and the linear fit (dashed line).

the second. At the end of this period, convection has produced a mean positive temperature anomaly in the deep layer, over the convection area, of $0.03^{\circ} \mathrm{C}$.

(3) From March 6 to April 25 the surface layer warms up slowly. It is important to notice that, except at the very end (mid April), the mean atmospheric (Péridot) forcing keeps removing heat from the ocean. Horizontal advection must be invoked to explain this surface warming. At the deeper layer the same relaxation toward initial condition occurs, rapidly in the first week, and then more slowly. According to Hermann and Owens [1993], during the first week the evolution is dominated by the sinking due to the adjustment process, and it proceeds by a horizontal spreading phase. A significant late cooling event occurs the last week of March; it temporarily cools the surface layer and halts the warming of the LIW layer but has no effect on the deep layer.

The heat content variation (gain or loss) of the ocean between 0 and $1500 \mathrm{~m}$ is compared to the surface cumulated flux (the atmosphere contribution). As shown by Figure 10, the ocean heat loss is systematically smaller than the heat removed by the atmosphere. The difference observed between those quantities shows a clear trend, modulated by time-varying events, which corresponds to an average flux deficit of $45 \mathrm{~W} \mathrm{~m}^{-2}$. This difference is above the estimated $20 \mathrm{~W} \mathrm{~m}^{-2}$ error on the surface fluxes. The deficit can be explained by an export of cold to (or an import of heat from) the surrounding area by advective processes. In the present situation, advection acts to reduce vertical exchanges, At the beginning it delays the convection process. When mixing has occurred it contributes to the export of anomalous water masses at intermediate level, and reduces the sinking.

The delays introduced by advection can be estimated by considering that convection occurs when the cumulated heat loss reaches a critical value $H_{c}$. In our case for an initial time $t=0$ on December 17, assuming that on average convection occurs on February 23 (time $t_{c}$ ), Figure 10 gives $H_{c}=-5.0 \times 10^{8} \mathrm{~J} \mathrm{~m}^{-2}$ (corresponding to a thermal contribution of $246 \mathrm{~N} \mathrm{~m}^{-2}$ to the buoyancy loss). The mean heat gain by the ocean during 
this period $\left(Q_{0}\right)$ results from the heat flux through the surface $\left(Q_{s}\right.$, equal to $\left.-Q_{h l}\right)$ and fluxes by horizontal advection $\left(Q_{a}\right)$ if we neglect vertical exchanges deeper than $1500 \mathrm{~m}$ :

$$
Q_{o}=Q_{s}+Q_{a}=H_{c} / t_{c}
$$

The convection time $t_{c}$ is given by

$$
t_{c}=\frac{H_{c}}{Q_{s}+Q_{a}}=t_{c}^{*}+t_{a}
$$

where $t_{c}^{*}=H_{c} / Q_{s}$ is the convection time prescribed by the atmospheric forcing alone and $t_{a}$ is the delay introduced by advection. This delay is positive when $Q_{a}>0$.

Table 5 shows the delays introduced by advection for increasing values of the surface fluxes and two values of ocean advection: The first value, $Q_{a}=45 \mathrm{~W} \mathrm{~m}^{-2}$, is given by our estimation (deduced by taking a mean atmospheric forcing before convection $Q_{s}=130 \mathrm{~W} \mathrm{~m}^{-2}$ ); the second value, $Q_{a}=25 \mathrm{~W} \mathrm{~m}^{-2}$, corresponds to the lower bound for the surface heat loss $Q_{s}=110 \mathrm{~W} \mathrm{~m}^{-2}$ (Péridot minus $20 \mathrm{~W} \mathrm{~m}^{-2}$ ). The retarding effect of advection is important with moderate forcing, delaying convection by 15 to 20 days, but it has negligable effect (only a few days) in the case of intense cooling. This confirms the modeling results of Madec et al. [1991b] and shows that advection can enhance the effects of the surface fluxes interannual variability on convection.

4.4.2. Deep water formation. During the 19911992 winter, convection has transfered heat and salt to the deep layers. The analysis of historical data performed by Béthoux et al. [1990] and later by Rohling and Bryden [1992] revealed that the deep western Mediterranean has been warming up since the last 1950, at a rate of $4 \times 10^{-30} \mathrm{C} \mathrm{y}^{-1}$ [Béthoux et al., 1990] or $1.6 \times 10^{-30} \mathrm{C} \mathrm{y}^{-1}$ [Rohling and Bryden, 1992]. These last authors concluded that the Mediterranean is not presently in equilibrium. Our volume estimates permit calculation of heat injected in the deep layers and evaluation of its contribution to the observed warming.

Immediately after convection, the situation can be sketched as follows: a homogeneous column of density $\rho_{1}$, surrounded by a lighter layer of density $\rho_{0}$, overlies a heavier layer of density $\rho_{2}$ (Figure 11). The maximum volume of new water that may be injected in layer 1 ,

Table 5. Delays Introduced by Advection

\begin{tabular}{rrrrr}
\hline$Q_{s}, \mathrm{~W} \mathrm{~m}^{-2}$ & $t_{c *}$, days & Delay, days $^{a}$ & Delay, days $^{b}$ \\
\hline 110 & 52.6 & $\ldots$ & & \\
130 & 44.5 & 23.5 & $\ldots .4$ \\
200 & 28.9 & 8.4 & & 4.2 \\
300 & 19.3 & 3.4 & & 1.7 \\
\hline
\end{tabular}

\footnotetext{
${ }^{a}$ Computed with $Q_{a}=-45 \mathrm{~W} \mathrm{~m}{ }^{-2}$, deduced from Péridot fluxes.

${ }^{b}$ Computed with $Q_{a}=-25 \mathrm{~W} \mathrm{~m}^{-2}$, obtained by reducing Péridot fluxes by $20 \mathrm{~W} \mathrm{~m}^{-2}$.
}
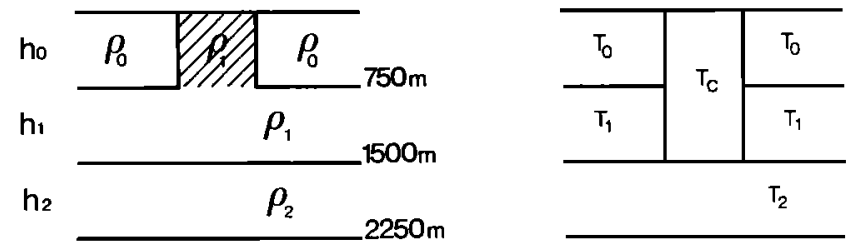

Figure 11. Situation at the end of convection. The shaded area represents the new water which is formed by converting surface and LIW into deep water.

$V_{n}$, is the part of layer 0 which has now density $\rho_{1}$ (the shaded area on Figure 11): $V_{n}=h_{0} A_{c}$, where $A_{c}$ is the convection area. If part of this water is mixed within layer 0 by horizontal exchange between the chimney and the outside region, only the fraction $\alpha V_{n}$ (with $0 \leq$ $\alpha \leq 1$ ) of new water is formed. The maximum flux of newly formed water, obtained with $\alpha=1$ and taking $h_{0}=750 \mathrm{~m}, A_{c}=2.0 \times 10^{10} \mathrm{~m}^{2}$ is

$$
\frac{V_{n}}{1 \text { year }}=0.48 \mathrm{~Sv}
$$

This number is intermediate between the estimation of SSGD (0.3 Sv) and (M. Rhein, personal communication, 1995) (1.2 Sv). The first estimate is very similar to ours; it is based on acoustic data only and considers a smaller but thicker volume $V_{n}$. The second is deduced from a fit between freons model concentration and measurements. The estimation given by the above equation is purely static. We assume that $V_{n}$ is formed, and then evacuated in the deep layer. If convection lasts several days and horizontal advection is efficient, as is the case here, the formation phase and spreading of the newly formed water phase overlap and the total volume of newly formed water is larger than the $V_{n}$ defined by the convection chimney (the volume may be filled more than once). This may explain the difference with the $1.2 \mathrm{~Sv}$ given by the tracer measurement.

Despite the uncertainties on this volume estimate, the order of magnitude of the resulting variation of the western Mediterranean deep temperature is examined. The heat $Q_{1}$ effectively transfered to layer 1 depends on $\alpha$ :

$$
Q_{1}=\rho C_{p}\left(\alpha h_{0}+h_{1}\right) A_{c}\left(T_{c}-T_{1}\right)
$$

where $T_{c}$ is the temperature of the convected water. If this water spreads horizontally in layer 1 over the surface of the western Mediterranean $\left(A_{w m}\right.$ the resulting yearly warming writes:

$$
\delta T_{1}=\frac{A_{c}}{A_{w m}}\left(\alpha \frac{h_{0}}{h_{1}}+1\right)\left(T_{c}-T_{1}\right) .
$$

From our volume estimate, $\left(T_{c}-T_{1}\right)=0.03^{\circ} \mathrm{C}, h_{1}=$ $750 \mathrm{~m}$, so

$$
0.7 \times 10^{-3} \leq \delta T_{1} \leq 1.4 \times 10^{-3 \circ} \mathrm{C}
$$

which agrees in magnitude with the mean warming of the western Mediterranean as estimated by Rohling and Bryden [1992], although for this year, only the layer $750-1500 \mathrm{~m}$ is modified. 
However, convection does not have the same characteristics every year; there is strong interannual variability both in the depth of penetration and in the final deep temperature [Mertens, 1994]. If one accepts the hypothesis that deep warming is brought about by the downward mixing of LIW through deep convection, the water must be cooled enough to increase its density and sink but not cooled so much that it becomes colder than the preexisting deep water. Clearly, as mentioned above, buoyancy fluxes and salinity must be considered. Some numbers are instructive: the initial heat content (with respect to the deep water at $12.78^{\circ} \mathrm{C}$ ) is equal to $1.4 \mathrm{GJ} \mathrm{m}^{-2}$; that is the amount of heat to be removed to bring the temperature of the water column to $12.78^{\circ} \mathrm{C}$. This is equivalent to a mean flux of $178 \mathrm{~W} \mathrm{~m}^{-2}$ acting for 91 days. Larger (smaller) losses will result in anomalously cold (warm) deep water. Mertens [1994] modeled surface fluxes from 1968 to 1992 ; rather coincidently he found the mean flux over the three winter months (December-February) to be $170 \mathrm{~W} \mathrm{~m}^{-2}$, with roughly half the winters above and half below that value. Thus deep water can be warmed by convection provided that simultaneously $\int_{0}^{t} Q_{B}>g L \Delta \rho \simeq 400 \mathrm{~N} \mathrm{~m}^{-2}$ (for the water to mix down) and $\int_{0}^{t} Q_{h l}<1.4 \mathrm{GJ} \mathrm{m} \mathrm{m}^{-2}$ (so that it is not cooled too much). It is only for the severe winter of 1987 that in situ observation documented deep cooling due to convection.

Our conclusion is that during the 1991-1992 winter, the amount of heat transfered to depth (above $1500 \mathrm{~m}$ ), in the Gulf of Lion, is compatible with the long-term trend reported by Béthoux et al. [1990] and Schott and Leaman, [1991]. However, the interannual variability of the convection process is such that this result cannot be extrapolated to other years. Accurate modeling would require three-dimensional models, consideration of buoyancy fluxes (and not just heat fluxes), and the possibility that convection is probably taking place in other areas (Ligurian Sea, for instance).

\section{Conclusion}

Temperature turns out to be a good marker of water mass changes as they occur during winter convection. It is also the parameter most commonly measured by the various in situ devices. Consequently, temperature has been chosen for performing the analysis of the convective event observed during the THETIS 1 experiment.

This paper has presented a method for analyzing a parameter which is made available from diverse types of measurements. The objective analysis technique used treats the various data sets within a unifying systematic framework, with clear assumptions on the length scales that can be observed. Each data point is injected in the analysis when and where it becomes available. The estimated field is thus resolved by combining the various spectral windows in time and space, providing a time-evolving three-dimensional representation of the field. The local effect of mesoscale processes which usually disturbs the budget estimations can be reduced by performing volume averages. We can now have access to more reliable estimates of the heat content evolution.

Surface forcing data from the Péridot model have been analyzed to produce surface heat and buoyancy fluxes during the same period. The simple one-dimensional mixed layer model, driven by the atmospheric buoyancy fluxes, indicates that convection would occur sooner, deeper, and over a larger area than what is observed. This confirms previous modeling studies showing that the purely vertical view is not sufficient and that some horizontal advection is taking place. The same conclusion is drawn from the heat flux analysis. There is a deficit of $45 \mathrm{~W} \mathrm{~m}^{-2}$ when comparing the surface heat flux given by Péridot to the time evolution of the heat content of the water column inside the Gulf of Lion estimated by the temperature analysis. The Gulf of Lion exchanges heat with the surrounding areas, the net effect being an export of the local cooling and a delay in convection.

At the beginning of winter we observe a strong stratification in the upper layers. Significant mesoscale activity is present, introducing high horizontal variability of the heat and buoyancy contents. Thus the traditional view of preconditioning must be somewhat revised: while there is a definite net loss of heat and stability in the upper layers during the winter cooling season, horizontal advection continuously redistributes and modifies properties within the gulf. The overall effect of mesoscale advection (or advection of mesoscale structures by the mean current) is to decrease the efficiency of surface cooling and delay the onset of deep convection. The absence of a clear well-mixed layer indicates also that some form of advection must intervene in the upper layers.

On the other hand, maps of buoyancy loss in the upper $1000 \mathrm{~m}$ show that the largest changes are observed in the NMC, near the coast, in the northeast. During the same period, the strongest surface heat losses occur in the northwest (Péridot). A possible explanation is that the import of warm water into the Gulf by the NMC is reduced. This precursor of convection is also seen in the horizontal maps of temperature as an early deep warming. This indicates that the Gulf of Lion is influenced by the upstream conditions and in particular by what has occurred in the Ligurian Sea.

Convection mixes relatively cold and fresh surface water with warmer, saltier Levantine Intermediate Water. The resulting dense water formed sinks to about $1500 \mathrm{~m}$, where it is warmer and saltier than the surrounding, older, deep water, as had already been observed by Stommel [1972]. By late April the field has not yet returned to its initial conditions; in particular, the deficit in LIW has not been compensated. Given the observed volume of newly formed anomalous water and assuming that it will eventually mix into the western basin, estimates of the resulting temperature increase are compatible, for this winter, with the warming trend reported by Rohling and Bryden [1992]. The deep (depth larger than $2000 \mathrm{~m}$ ) potential temperatures observed during the THETIS cruises, $\theta \simeq 12.78^{\circ} \mathrm{C}$, con- 
firm that the warming trend is continuing and that the western Mediterranean basin is not in a steady state.

\section{Appendix A: The Kalman Filter}

We recall here the definition of the Kalman filter as it is given by Bennet [1992] and describe how the general form has been simplified for our particular application. The state vector $x_{n}$ is the set of parameters describing the field we wish to estimate at time $t_{n}$, and $y_{n}$ is the vector of the data available for this time step. We assume a linear relationship between data and parameters in the form

$$
y_{n}=G_{n} x_{n}
$$

At each updating step, the first-guess $x_{n}^{0}$ is improved by applying the Kalman gain $H_{n}$ to the innovation vector $\left(y_{n}-G_{n} x_{n}^{0}\right)$ :

$$
\begin{aligned}
x_{n} & =x_{n}^{0}+H_{n}\left(y_{n}-G_{n} x_{n}^{0}\right) \\
C_{n}^{e} & =\left(I-H_{n} G_{n}\right) C_{n}^{x^{\prime}} \\
H_{n} & =C_{n}^{x^{\prime}} G_{n}^{T}\left(G_{n} C_{n}^{x^{\prime}} G_{n}^{T}+C_{n}^{\epsilon}\right)^{-1}
\end{aligned}
$$

$C_{n}^{x^{\prime}}$ and $C_{n}^{e}$ are the a priori and a posteriori covariance matrices, respectively, of the state vector, while $C_{n}^{\epsilon}$ is the covariance matrix of the data error. The time evolution of the state vector is governed by the predictive equation

$$
x_{n}=P_{n-1} x_{n-1}+r_{n}
$$

where $r_{n}$ is the prediction error. A forecast step predicts the a priori estimate $x_{n}^{0}$ and the matrix of second-order moments $C_{x_{n+1}^{\prime}}$ :

$$
\begin{aligned}
x_{n}^{0} & =P_{n-1} \hat{x}_{n-1} \\
C_{n}^{x^{\prime}} & =E\left[\left(x_{n}-x_{n}^{0}\right)\left(x_{n}-x_{n}^{0}\right)^{T}\right] \\
& =P_{n-1} C_{n-1}^{e} P_{n-1}^{T}+R_{n} .
\end{aligned}
$$

In the spectral representation the initial a priori covariance matrix $C_{1}^{x^{\prime}}$ is computed from the spectrum of the horizontal covariances for each vertical mode. The horizontal covariances are assumed Gaussian, with efolding scales of $20 \mathrm{~km}$ for modes 1 and 2 and $15 \mathrm{~km}$ for modes 3, 4, and 5. Such values, which seem large compared to the Rossby radius, are chosen to avoid imposing unnecesary small scales to the field. The data set will adjust the scales at each updating step as pertinent information comes into the system. The data error covariance matrix $C_{n}^{\epsilon}$ is diagonal and built from the knowledge we have of the different measurement errors.

The forecast equation assumes the persistance of the field with limited memory. The full prediction equation is damped by climatology:

$$
\begin{aligned}
x_{n} & =\mu x_{n-1}+(1-\mu) x_{e}+r_{n} \\
\mu & =\exp \left(\frac{t_{n}-t_{n-1}}{t_{m}}\right)^{2}
\end{aligned}
$$

In the present case, the climatological state is the unperturbed state: $x_{c}=0$. The size of our state vec- tor $(O(1000)$ unknowns) permits application of the full Kalman filter: the covariance matrix $C_{n-1}^{e}$ is computed at each updating step. The prediction error is assumed random, as is the a priori covariance at the initial time. It is decided to define this covariance $R_{n}$ as a percentage of $C_{1}^{x^{\prime}}$. The influence of the memory time and of the form of the prediction error has been studied by Lannuzel and Gaillard [1994]. Using the results of this work, the memory time is set to 8 days and the prediction error is taken as $17 \%$ of the climatological RMS over the 12-hour forecast step.

\section{Appendix B: Errors on Atmospheric Fluxes}

The Péridot data are provided on a grid $1 / 3^{\circ}$ in longitude and $1 / 4^{\circ}$ in latitude. They consist of twice daily values of 12-hour integrated sensible and latent heat fluxes $\left(Q_{h}\right.$ and $\left.Q_{\ell}\right)$, incoming short wave radiation $\left(Q_{s}\right)$, and incoming long wave atmospheric radiation $\left(Q_{b} \downarrow\right)$. The values of the long wave radiation from the sea surface, $Q_{b} \uparrow$, were not provided. We estimate it roughly as $Q_{b} \uparrow=\epsilon \sigma T^{4}$, with $T \approx 13^{\circ} \mathrm{C}, \epsilon=0.985$ (the water emittance, i.e., the departure from black body radiation), and $\sigma=5.7 \times^{-8} \mathrm{~W} \mathrm{~m}^{-2} \mathrm{~K}^{-4}$ (Stefan's constant); we have then $Q_{b} \uparrow \approx 376 \mathrm{~W} \mathrm{~m}^{-2}$.

Mertens [1994] and SSGD have discussed the possible errors on the Péridot fluxes. The essential points of their analysis are that (1) Péridot overestimates the net long wave radiation losses $\left(Q_{b}\right)$ by an average bias of $32 \mathrm{~W} \mathrm{~m}^{-2}$, (2) Péridot underestimates winds by $37 \%$, with a corresponding time-dependent underestimation of sensible and latent heat fluxes $\left(Q_{h}\right.$ and $Q_{\ell},(3)$ a correction on the short wave incoming radiation $\left(Q_{s}\right)$ of $+20 \mathrm{~W} \mathrm{~m}^{-2}$ is needed, and (4) the net result of all those corrections (averaged over 3 months) is an increase of only $10 \mathrm{~W} \mathrm{~m}^{-2}$ over the Péridot values. To be conservative, SSGD assume the fluxes to be accurate to $\pm 20 \mathrm{~W} \mathrm{~m}^{-2}$.

Some further comments are added here to emphasize how difficult it is to refine those errors estimates. For instance, a change in the value of the water emittance $(\epsilon)$ in the term $Q_{b} \uparrow=\epsilon \sigma T^{4}$ from 0.96 (as given by Mertens, [1994]) to 0.98 [Schiano et al., 1993] increases the loss by $7.6 \mathrm{~W} \mathrm{~m}^{-2}$; a $1^{\circ} \mathrm{C}$ increase in SST (from 13 to $14{ }^{\circ} \mathrm{C}$ ) increases $Q_{b} \uparrow$ by $5.2 \mathrm{~W} \mathrm{~m}^{-2}$.

Schiano et al. [1993] report observations of $Q_{s}$ made on a platform in the Tyrrhenian Sea in February 1990. They give values of $Q$, ranging from 134.6 to 163.7 $\mathrm{W} \mathrm{m} \mathrm{m}^{-2}$, with a mean of $139.7 \mathrm{~W} \mathrm{~m}^{-2}$. The corresponding Péridot values are 130 to $165 \mathrm{~W} \mathrm{~m}^{-2}$, with a mean of $147 \mathrm{~W} \mathrm{~m}^{-2}$, for the same period of February 1992, i.e., an overestimation of only $7 \mathrm{~W} \mathrm{~m}^{-2}$.

We have no data on precipitation over the Gulf of Lion, but the Bulletin Climatique Annuel [Météo France, 1992 and 1993] reports monthly values of precipitation at coastal stations; the average values over a few representative sites (Marignane, Toulon, and Saint Raphael) range from a low of $1 \mathrm{~mm}$ in December to a high of $34 \mathrm{~mm}$ in March, with a total of $103 \mathrm{~mm}$ for the 4-month 
Table A1. Comparison of Precipitation Estimates to Péridot Buoyancy Fluxes (Fluxes are given in $10^{-5} \mathrm{~N} \mathrm{~m}^{-2} \mathrm{~s}^{-1}$.)

\begin{tabular}{lrrrr}
\hline \multicolumn{1}{c}{ Period } & Precipitation & $\left\langle Q_{B e}\right\rangle$ & $\left\langle Q_{B}\right\rangle$ & $100\left(P /\left\langle Q_{B}\right\rangle\right)$ \\
\hline & & & & \\
December & 0.01 & 1.72 & 11.64 & 0.1 \\
January & 0.31 & 0.82 & 6.72 & 4.6 \\
February & 0.33 & 1.16 & 6.31 & 5.2 \\
March & 0.44 & 1.27 & 3.63 & 12.1 \\
April & 0.27 & 1.32 & 0.66 & 40.9 \\
December - April & 0.34 & 1.26 & 5.71 & 6.0 \\
& & & & \\
\hline
\end{tabular}

period. Accepting those values as order of magnitude estimates over the gulf, they can be converted to buoyancy fluxes, which are compared to the Péridot values in Table A1. The contributions of precipitation are relatively small, particularly during the first months of vigourous cooling.

Over the first 3 months, the corrections suggested by SSGD would increase the thermal losses by about $10 \%$ and the haline buoyancy loss by $37 \%$. The ratio $\left\langle Q_{B e}\right\rangle /\left\langle Q_{B}\right\rangle$ increases then from 0.21 to 0.26 . Given the above uncertainties, we will accept the Péridot values, with the $20 \mathrm{~W} \mathrm{~m}^{-2}$ uncertainty. Since only overall budgets are considered (over the first 45 days and then the following 40 days), the modifications in the time history of the fluxes related to the wind speed correction are not significant.

Error estimates on the buoyancy fluxes are obtained as follows: since the thermal effect dominates the buoyancy fluxes (see Table $\mathrm{A} 1$ ), $\delta Q_{h l}=20 \mathrm{~W} \mathrm{~m}^{-2}$ is equivalent to $\delta Q_{B}=\left(g \alpha / c_{w}\right) \delta Q_{h l}=9.65 \times^{-6} \mathrm{~N} \mathrm{~m}^{-2} \mathrm{~s}^{-1}$, which, integrated over 45 days, gives an error of 37.5 $\mathrm{N} \mathrm{m}^{-2}$. Similarly, the error over the next 40 days would be $33.3 \mathrm{~N} \mathrm{~m}^{-2}$, for a total of $70.8 \mathrm{~N} \mathrm{~m}^{-2}$ over the first 85 days. Those are the values used in section 4.2.2.

Acknowledgments. T. Terre developed the software that made possible the systematic processing of the large volume of acoustic data which enters this analysis. The experiment and project was funded by the European Community MAST program (contract MAST 0008-C), the German Ministry of Science and Technology (BMFT, contract 03F0542A), IFREMER, and the Programme Atmosphère Météorologique et Océan Superficiel (CNRS).

\section{References}

Bennet, A. F., Inverse Methods in Physical Oceanography, Cambridge Univ. Press, New York, 1992.

Béthoux, J.-P., B. Gentili, J. Raunet, and D. Taillez, Warming trend in the western Mediterranean deep water, $\mathrm{Na}$ ture, 347, 660-662, 1990.

Brasseur, P., J.-M. Blankart, and J.M. Beckers, Seasonal variability of general circulation fields in the Mediterranean sea: Inventory of climatological fields. MODB report, GeoHydrodynamics and Environment Research, Univ. of Liège, Belgium, 1994.

Clarke, R. A., and J.-C. Gascard, The formation of Labrador Sea water, I, Large-scale processes, J. Phys. Oceanogr., 13, 1764-1778, 1983.
Gaillard, F., Evaluating the information content of tomographic data: Application to mesoscale observations, $J$. Geophys. Res., 97, 15,489-15,505, 1992.

Garrett, C., The Mediterranean Sea as a climate test basin, in Ocean Processes on Climate Dynamics: Global and Mediterranean Examples, edited by P. Malanotte-Rizzoli, and A.R. Robinson, pp 227-237, Kluwer Acad., Dordrecht, Netherlands, 1994.

Gascard, J.-C., Vertical motions in a region of deep water formation, Deep Sea Res., 20, 1011-1027, 1973.

Gascard, J.-C., Mediterranean deep water formation, baraclinic instability and oceanic eddies, Oceanol. Acta, 1, 315-330, 1978.

Gascard, J.-C., and C. Richez, Water masses and circulation in the Western Alboran Sea and in the Straits of Gibraltar, Prog. Oceanogr., 15, 157-216, 1985.

Gill, A. E., Atmosphere-Ocean Dynamics, 662 pp., Academic P., San Diego, Calif., 1982.

Greenland Sea Project Group, Greenland Sea Project - A venture towards improved understanding of the oceans' role in climate, Eos Trans. $A G U, 71(24), 750-751,754-$ 756,1990

Herbault, C., Etude de la circulation en Méditerranée occidentale, Ph. D. thesis, Univ. de Paris 6, Paris, France, 1995.

Hermann, A. and B. Owens, Energetics of gravitational adjustment for mesoscale chimneys, J. Phys. Oceanogr., 23, 346-371, 1993.

Hogg, N. G., The preconditioning phase of MEDOC 1969, II, Topographic effects, Deep Sea Res., 20, 449-459, 1973.

Jones, H., and J. Marshall, Convection with rotation in a neutral ocean: A study of open-ocean deep convection, $J$. Phys. Oceanogr., 23, 1009-1039, 1993.

Killworth, P. D., The mixing and spreading phase of MEDOC I, Prog. Oceanogr., 7, 59-90, 1976.

Lannuzel, S., and F. Gaillard, Assimilation de données de tomographie par l'utilisation du filtrage de Kalman, Projet de fin d'étude, Ecole Nationale Supérieure des Ingénieurs des Etudes et Techniques de l'Armement, Brest, France, 1994.

Leaman, K., and F. Schott, Hydrographic structure of the convection regime in the Golfe du Lion, J. Phys. Oceanogr., 21, 575-598, 1991.

Madec, G., M. Chartier, P. Delecluse, and M. Crépon, A three-dimensional numerical study of deep-water formation in the North-Western Mediterranean sea, J. Phys. Oceanogr., 21, 1349-1371, 1991a.

Madec, G., M. Chartier, and M. Crépon, The effect of thermohaline forcing variability on deep water formation in the western Mediterranean sea: A high-resolution threedimensional numerical study, Dyn. Atmos. Oceans, 15 , 301-332, 1991b.

Méditerranée Occidentale (MEDOC) Group, Observation of formation of deep water in the Mediterranean, Nature, 227, 1037-1040, 1970. 
Mertens, C., Winterlische Deckschichtentwicklung und ihre zwischenjaerliche Variabilitaet im nordwestlischen Mittelmeer, diploma thesis, Univ. of Kiel, Kiel, Germany, 1994.

Météo France, Bulletin Climatique Annuel 1991, Dir. de la Météorol. Nat., Paris, France, 1992.

Météo France, Bulletin Climatique Annuel 1992, Dir. de la Météorol. Nat., Paris, France, 1993.

Ozturgut, E., The sources and spreading of the Levantine Intermediate Water in the Eastern Mediterranean, Saclant ASW Res. Cent., Tech. Memo., SM-92, La Spezia, Italy, 1976.

Rohling, E. J., and H. L. Bryden, Man-induced salinity and temperature increases in the western Mediterranean deep water, J. Geophys. Res., 97, 11,191-11,198, 1992.

Sankey, T., The formation of deep water in the northwestern Mediterranean, Prog. in Oceanogr., 6, 159-179, 1973.

Schiano, M. E., R. Santoleri, F. Bignami, R. M. Leonardi, S. Marullo, and E. Bohm, Air-sea measurements in the west Mediterranean Sea during the Tyrrhenian eddy multiplatform observations experiment, J. Geophys. Res., 98, 2461-2474, 1993.

Schott, F., and K. Leaman, Observations with moored acoustic Doppler current profilers in the convection regime in the Golfe du Lion, J. Phys. Oceanogr., 21, 558-574, 1991.

Schott, F., M. Visbeck and J. Fischer, Observations of vertical currents and convection in the central Greenland Sea during the winter of 1988-1989, J. Geophys. Res., 98, 14,401-14,421, 1993.

Schott, F., M. Visbeck und U. Send, Open ocean deep convection, Mediterranean and Greenland Seas. In Ocean Processes on Climate Dynamics: Global and Mediterranean Examples, Malanotte-Rizzoli, P. and A.R. Robin- son (eds.) 203-225. Kluwer Academic Publishers, Netherlands, 1994.

Schott, F., M. Visbeck, U.Send, J. Fischer, L. Stramma, and Y. Desaubies, Observations of deep convection in the Gulf of Lions, northern Mediterranean, during the winter of 1991-1992, J. Phys. Oceanogr., 26, 505-524, 1995.

Send, U., and J. Marshall, Integral effects of deep convection, J. Phys. Oceanogr., 25, 855-872, 1995.

Send, U., F. Schott, F. Gaillard, and Y. Desaubies, Oberservation of a deep convection regime with acoustic tomography, J. Geophys. Res., 100, 6927-6941, 1995.

Stommel, H., Deep winter-time convection in the western Mediterranean Sea, in Studies in Physical Oceanography, a tribute to George Wust on His 80th Birthday, edited by A.L. Gordon, pp. 207-218, Gordon and Breach, Newark, N.J., 1972.

Swallow, J.C., and G.F. Caston, The preconditionning phase of MEDOC 69, I, Observations, Deep Sea Res., 20, 429448, 1973.

The Theoretical and Experimental Tomography in the Sea Experiment (THETIS) Group, Open-ocean deep convection explored in the Mediterranean. Eos Trans. $A G U$, 75(19), 217,219-221, 1994.

Y. Desaubies and F. Gaillard, Laboratoire de Physique des Océans, Institut Français de Recherche pour l'Exploitation de la Mer, BP 70, 29280 Plouzané, France. (e-mail: fabienne.gaillard@ifremer.fr)

F. Schott and U. Send, Institut für Meereskunde, Dūsterbrocker weg 20, 24105 Kiel, Germany.

(Received November 1, 1995; revised May 8, 1996; accepted September 27, 1996.) 